\title{
Estética em Ortodontia: Diagramas de Referên- cias Estéticas Dentárias (DRED) e Faciais (DREF)
}

\author{
Carlos Alexandre Leopoldo Peersen da Câmara*
}

\begin{abstract}
Resumo
Seria interessante que todas as especialidades odontológicas envolvidas com a Odontologia Estética utilizassem parâmetros estéticos dentários e faciais que fossem comuns a todos os profissionais. Considerando que essa tarefa só poderá ser exercida quando as especialidades puderem contar com análises estéticas simplificadas que sejam do entendimento de todos, esse trabalho propõe-se a apresentar os Diagramas de Referências Estéticas Dentárias e Faciais, que terão o intuito de prover uma avaliação da estética dentofacial, de uma forma simples, individualizada e subjetiva de cada paciente, e que servem como instrumentos de referência para todas as especialidades odontológicas, auxiliando no diagnóstico e planejamento dos tratamentos multidisciplinares.
\end{abstract}

Palavras-chave: Odontologia Estética. Ortodontia. Estética dentária. Estética bucal. Estética facial.

\section{INTRODUÇÃO}

Seria muito interessante que todas as áreas da Odontologia tivessem em comum a possibilidade de avaliar e reconhecer os requisitos morfológicos que interferem e influenciam a estética dentária e facial ${ }^{14}$. Seria como se pudéssemos avaliar as nossas obras de artes odontológicas com uma visão preparada para tal, sabendo por meios técnicos e científicos identificar os pontos chaves para esse reconhecimento. Não é fácil reconhecer o belo, trata-se de uma tarefa cerebral, que nem sempre pode ser bem explicada. Poderíamos perguntar: se uma imagem vale por mil palavras, será que mil palavras conseguem explicar uma imagem? E se essa imagem for bela? E ainda, o que é ser belo ou estético? Belo, segundo o dicionário Aurélio, é aquilo que é agradável aos sentidos ${ }^{29}$. Em outras palavras, é a expressão visual agradável do incog- niscível. Isto é, aquilo que conseguimos reconhecer como agradável mesmo sem perceber o porquê. Seria algo intuitivo ou talvez emotivo. É como diz o poeta Ernest Hello: "Beleza é a forma que o amor dá as coisas". E o que seria estético? É aquilo que tem característica de belezaa ${ }^{29}$. Avaliando essas definições podemos perceber o quanto elas são subjetivas. Não são suficientes para ajudar no reconhecimento dos fatores necessários para a execução de um tratamento odontológico, que tem por objetivo o melhor resultado estético. Precisamos criar maneiras de facilitar a nossa visualização, buscando de forma prática a obtenção de parâmetros para executar essa tarefa. Morfologia não se mede, se observa, mas embora a avaliação morfológica não seja uma tarefa para se obter com números, pode-se fazê-la com medições visuais, através de enquadramentos e comparações. A percepção de

* Especialista em Ortodontia pela FO-UER. Consultor científico da Revista Dental Press de Estética. Diplomado pelo Board Brasileiro de Ortodontia. 
proporções é uma boa maneira de se executar essa tarefa. Embora não seja definitiva e impassivel de erros, pode se tornar uma maneira facilitada de observar e compreender os erros e acertos que a leitura das proporções dentárias e faciais guardam entre si. Nesse contexto, a utilização de diagramas viria ajudar e facilitar o entendimento do que está sendo visto, buscando através de enquadramentos e comparações o que pode estar em acordo ou desacordo com o conjunto que está sendo observado. A utilização de diagramas de referências estéticas dentárias e faciais servirá para esse propósito, buscando simplificar e avaliar o que os números nem sempre conseguem explicar. Afinal, os números servem, quando muito, para nos dar uma idéia de um grupo estudado, mas quando falamos em estética: pacientes são estatísticas e clientes são pessoas.

Assim, sem procurar objetivar com números e buscando análises subjetivas que ofereçam comparações absolutamente individualizadas, foi o intuito desse trabalho ampliar a visão integrada do diagnóstico estético e artístico de todo o complexo dentofacial, provendo uma perspectiva dos aspectos dentários, bucais e faciais que podem ser influenciados pela integração entre a Ortodontia e as outras especialidades odontológicas e a sua contribuição na obtenção dos melhores resultados.

\section{DIAGRAMA DE REFERÊNCIAS ESTÉTICAS DENTÁRIAS (DRED)}

O Diagrama de Referências Estéticas Dentárias (DRED) define o que deverá ser criado ou alcançado com os dentes ântero-superiores. A finalidade desse diagrama é dar uma noção exata dos posicionamentos e proporções que os dentes guardam entre si e também a relação desses com a gengiva e os lábios. Esse diagrama é constituído de seis caixas que englobam os incisivos e caninos superiores; e os seus limites irão ser específicos para cada referência estética. Cada caixa irá englobar o seu respectivo dente, obedecendo aos seus limites. Embora essas caixas possam servir de referência nos vários planos de observação, o DRED será avaliado em uma visão de $90^{\circ}$ em relação ao plano frontal, ou seja, perpendicular a esse plano. $\mathrm{O}$ diagrama tem um conceito semelhante a outros diagramas apresentados na literatura ${ }^{6,67}$, apresentando, no entanto, sutis diferenças na sua concepção, sendo a principal a avaliação das linhas do sorriso, como será explicado adiante. A sua utilização facilitará o planejamento e a visualização do melhor posicionamento estético dos dentes anteriores, sendo o seu objetivo fornecer informações que possam auxiliar nas suas reorganizações e reestruturações, quando esses dentes tiverem que ser reposicionados e/ou restaurados. Naturalmente, a estética é algo subjetivo, entretanto, acredita-se que as regras gerais se aplicam a cada indivíduo ${ }^{6}$. Cada paciente tem o seu próprio diagrama de referência, que é determinado pelos dentes e estruturas adjacentes ${ }^{23}$. Caso o diagrama do paciente não esteja harmonioso e necessite ser mudado, o DRED servirá como modelo. Esse parâmetro geométrico não deve ser visto como imutável, mas como um guia útil para a obtenção de melhores resultados estéticos nos tratamentos odontológicos.

Com a utilização do DRED poderão ser visualizados (Fig.1):

- Simetria;

- Eixos dentários;

- Limite do contorno gengival;

- Nivel do contato interdentário;

- Bordas incisais;

- Proporções dentárias;

- Linhas do sorriso.

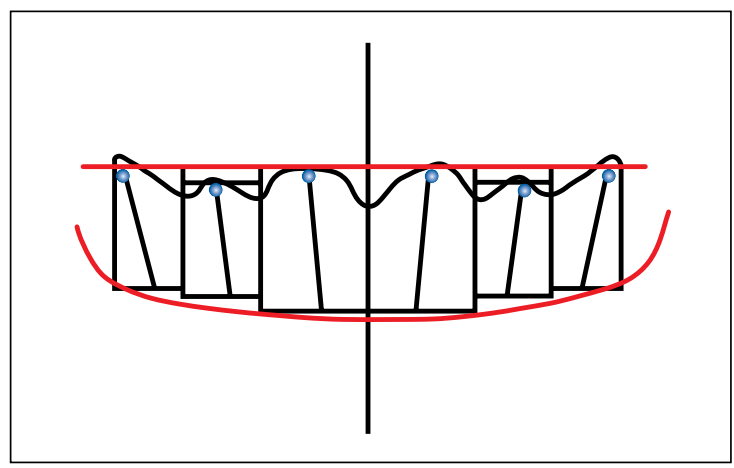

FIGURA 1 - Diagrama de Referências Estéticas Dentárias (DRED). 


\section{Simetria}

Os pares de dentes anteriores devem ser simétricos, em uma vista frontal. Isto é, o incisivo central superior direito deve ser do mesmo tamanho do incisivo central superior esquerdo, e assim respectivamente, para os incisivos laterais e caninos. Além disso, devem estar posicionados simetricamente; com a linha média da face coincidindo com a linha média dentária. Quanto mais próximo da linha média, mais crítica se torna, esteticamente, essa referência ${ }^{26}$. No entanto, não se deve superestimar a coincidência dessas linhas. As linhas médias facial e dentária coincidem em $70 \%$ das pessoas; as linhas médias superior e inferior não coincidem em quase três quartos da população $0^{47}$. Embora o objetivo de todo tratamento estético seja o posicionamento correto da linha média superior, nem sempre o desvio dessa referência é bem percebido por profissionais e pessoas leigas $^{35,37}$. O importante é que nos casos em que não é possível coincidir a linha média facial com a dentária, a linha entre os incisivos centrais superiores fique paralela à linha média facial. A inclinação da linha de junção entre os incisivos centrais é mais perceptível que o desvio das linhas médias ${ }^{37}$.

As caixas do DRED servirão para dar a noção de simetria. Como cada dente será representado por sua respectiva caixa, maus posicionamentos e desproporções de tamanho serão facilmente identificados. O ideal será sempre que as caixas do lado direito (incisivos lateral, central e canino direito) sejam um espelho das caixas do lado esquerdo (Fig. 2).

\section{Eixos dentários}

As inclinações e angulações dos dentes anteriores correspondem aos eixos dentários. Embora existam muitas medidas-padrão para esses eixos, cada tratamento deve obedecer ao padrão morfológico e estético do paciente ${ }^{15,16}$. Uma informação importante é que os dentes anteriores, assim como os posteriores, apresentam uma angulação positiva do eixo vestibular da coroa clínica. Isto é, a porção oclusal do eixo vestibular se posiciona mesialmente à porção gengival. Além disso, as angulações devem aumentar a partir dos incisivos centrais superiores para os caninos superiores. $\mathrm{O}$ contrário ocorre com as inclinações, onde a partir dos incisivos centrais superiores, elas diminuem em direção aos caninos ${ }^{1,2}$ (Fig. 3).

\section{Limite do contorno gengival}

$\mathrm{O}$ limite do contorno gengival deve seguir como referência o tamanho dos dentes anteriores, sendo

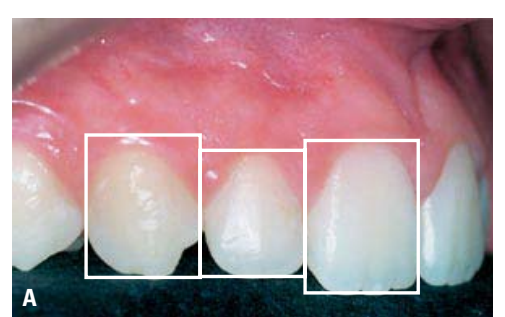

FIGURA 2 - Simetria.

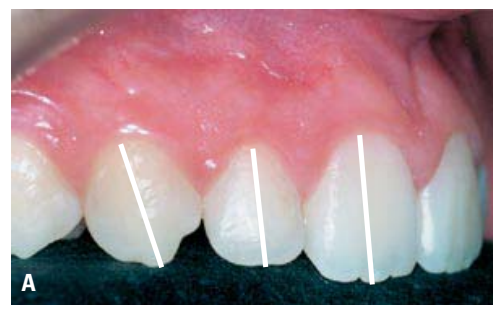

FIGURA 3 - Eixos dentários.
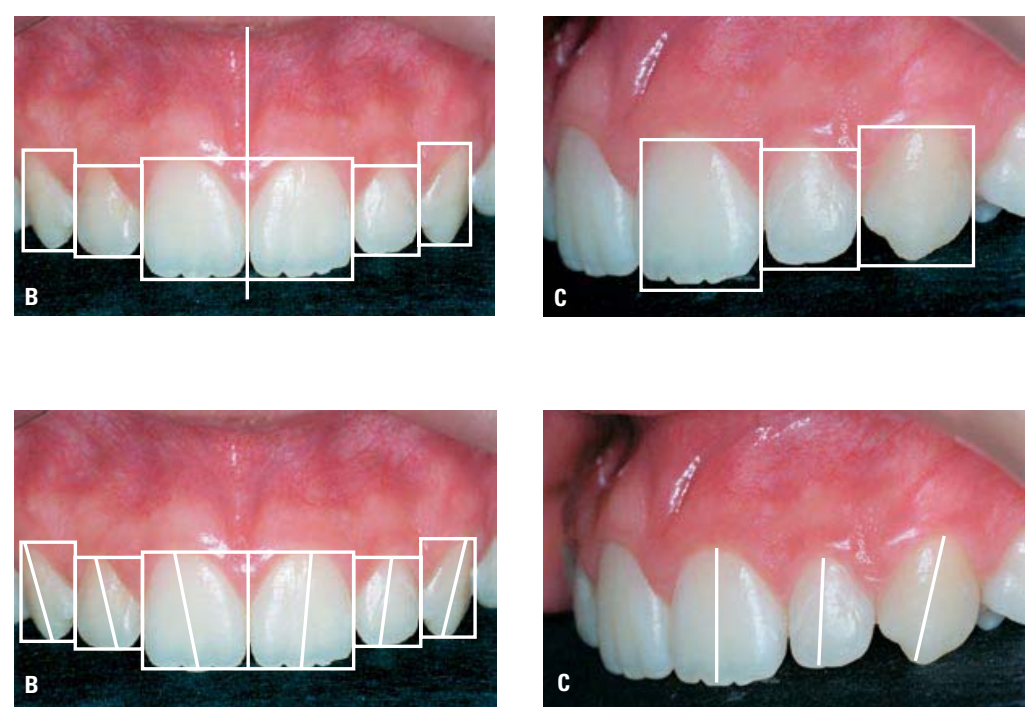
que os limites dos contornos gengivais dos caninos devem estar mais altos do que os incisivos laterais e, mais ou menos, na mesma altura dos incisivos centrais superiores. Essa situação ideal representa a altura gengival de Classe I. Variações moderadas relacionadas a esse critério são freqüentes. $\mathrm{Na}$ altura gengival de Classe II, o contorno gengival dos incisivos laterais situa-se apical aos incisivos centrais e caninos $^{63}$. Essa situação pode ser corrigida ortodonticamente, com movimentos intrusivos e/ou extrusivos de dentes. No caso de deformidades severas, a cirurgia plástica periodontal deve ser utilizada, a fim de otimizar os contornos gengivais para o tratamento restaurador ${ }^{32}$. O limite do contorno gengival será representado pelo Zenith gengival (ponto mais apical do tecido gengival). Entre o eixo vestibular da coroa clínica e o Zenith gengival haverá uma interseção, criando um ponto de referência ${ }^{18}$ (Fig. 4).

\section{Nível do contato interdentário}

$\mathrm{O}$ contato interdentário dos dentes ântero-su-
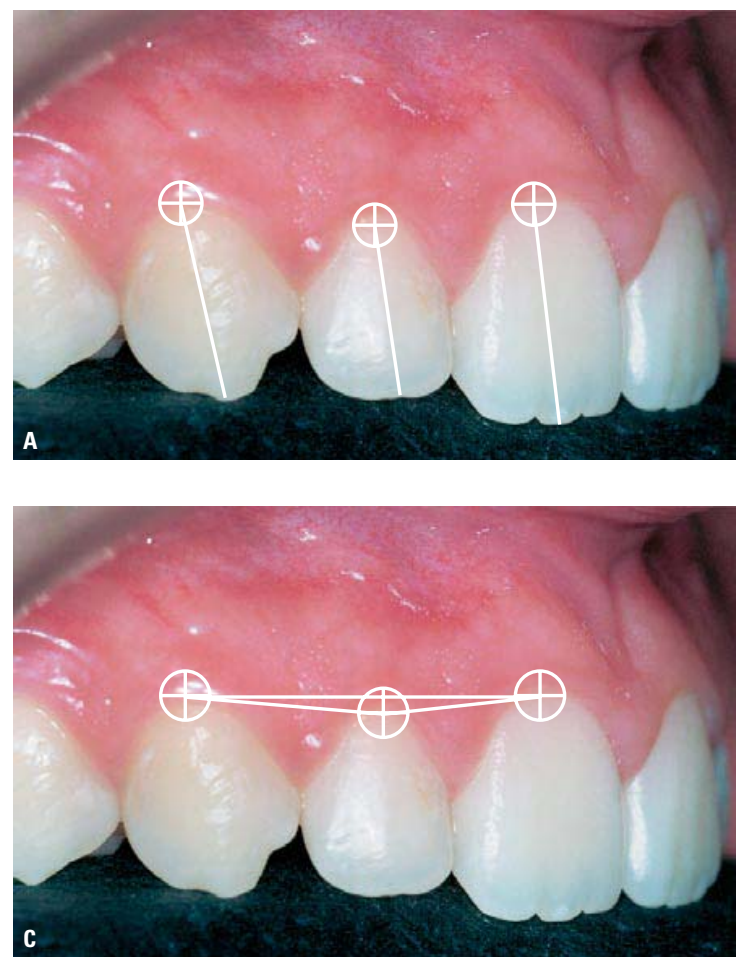

FIGURA 4 - Limite do contorno gengival. periores é feito de forma descendente, a partir do canino. $\mathrm{O}$ contato entre canino e incisivo lateral se posiciona mais alto do que o contato entre o incisivo lateral e central; o contato entre os incisivos centrais se posiciona mais baixo ainda. Esses pontos de contatos devem ser justos, a menos que exista uma discrepância no diâmetro mésio-distal da coroa $^{1,2}$. A posição do contato interdentário está relacionada à posição e morfologia do dente ${ }^{45}$ (Fig. 5).

\section{Bordas incisais}

As bordas incisais dos dentes anteriores devem criar uma forma de "prato fundo", onde os incisivos centrais se posicionam mais inferiormente aos incisivos laterais e caninos (Fig. 6).

\section{Linhas do sorriso (avaliação dinâmica)}

A visualização das "caixas dentárias" que compõem o DRED dará uma noção da relação que os dentes ântero-superiores guardam entre si.
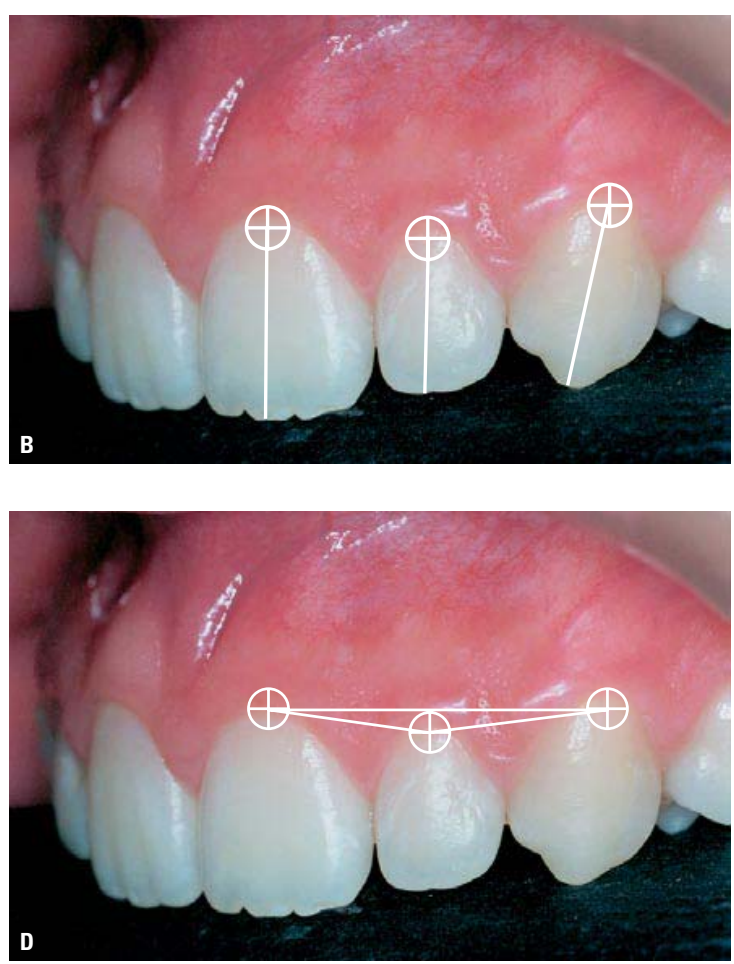


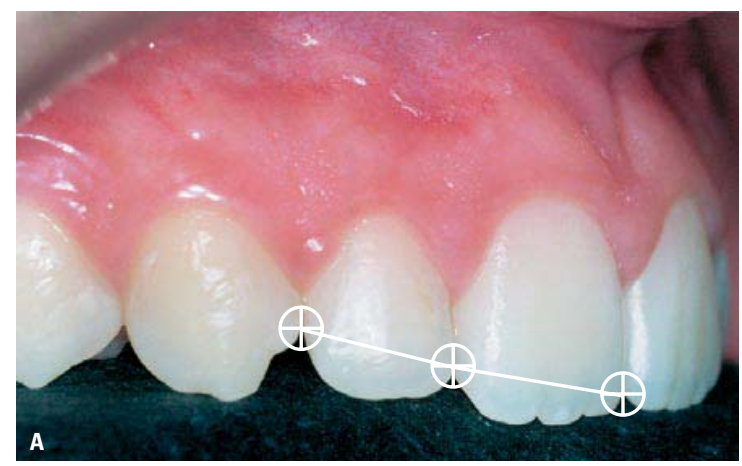

FIGURA 5 - Nível do contato interdentário.

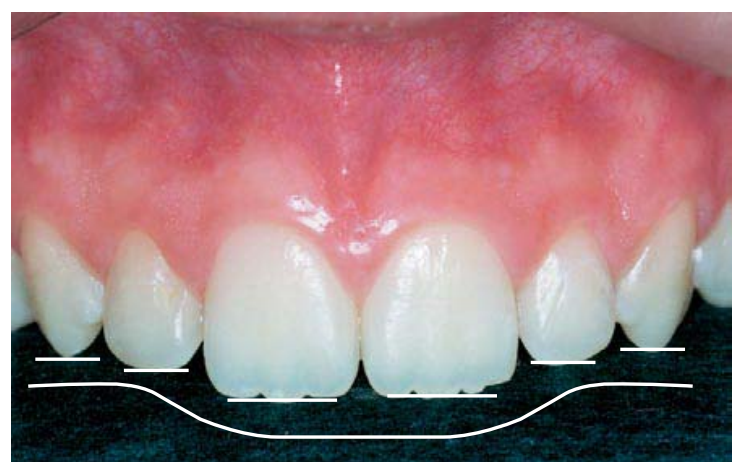

FIGURA 6 - Bordas incisais em forma de "prato fundo".

Porém, esta visão limita-se a uma avaliação estética exclusivamente dentária e estática. Acrescentando os limites labiais, pode-se fazer uma avaliação dinâmica da estética bucal durante o sorriso, na qual os dentes guardam uma relação harmoniosa com a posição e forma dos lábios, criando-se as linhas do sorriso. Uma exposição de incisivos superiores, durante o sorriso, variando de $30 \%$ a $70 \%$ nos homens e $70 \%$ a $100 \%$ nas mulheres, será considerada norma ${ }^{69}$. Para todas as análises a idade do paciente deve ser levada em consideração, pois a forma e a posição dos lábios mudam com a idade. Conforme o avanço da idade do paciente, o lábio superior cresce e perde a mobilidade e ocorre uma menor exposição dos dentes superiores. $\mathrm{O}$ inverso ocorre com os dentes inferiores. Quanto mais velho o indivíduo, maior a exposição dos dentes inferiores ${ }^{71}$. Quando o paciente sorri, o ideal seria que o lábio superior expusesse todas as coroas dos incisivos su-

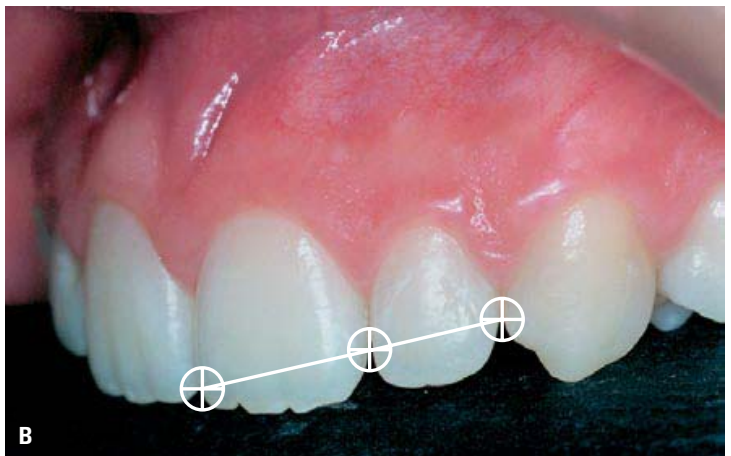

periores e $1 \mathrm{~mm}$ de gengiva. A exposição gengival de 2 a $3 \mathrm{~mm}$ também é esteticamente aceitável ${ }^{17}$. A exposição completa dos incisivos superiores nem sempre ocorre. O sorriso pode ser considerado baixo, médio ou alto, conforme a exposição desses ${ }^{59}$. Os extremos são sempre preocupantes, do ponto de vista estético. A exposição acentuada dos incisivos superiores provoca o "sorriso gengival" 36,41 . A falta de exposição causa o seu envelhecimento. A avaliação de fatores relacionados com a altura da linha do sorriso demonstra que as mulheres tendem a ter o sorriso mais alto que os homens $s^{54,59}$.

O tipo de sorriso também deve ser levado em consideração. Segundo a classificação de Rubin ${ }^{62}$, existem três tipos de sorriso: "monalisa", "canino" e "amplo". No sorriso de "monalisa", os cantos da boca são elevados pelos músculos zigomáticos maiores. No sorriso de "canino", o lábio superior é elevado uniformemente, e no sorriso "complexo", o lábio superior move-se superiormente, como no sorriso de "canino", mas o lábio inferior também se move inferiormente. Além do tipo de sorriso, devese observar os seus estágios. O sorriso se forma em dois estágios: o primeiro (sorriso voluntário) eleva o lábio superior em direção ao sulco nasolabial, pela contração dos músculos elevadores, que se originam neste sulco e tem inserção no lábio. Os feixes mediais elevam o lábio na região dos dentes anteriores e os laterais na região dos dentes posteriores. O lábio então encontra resistência, devida ao tecido adiposo das bochechas. O segundo estágio (sorriso 

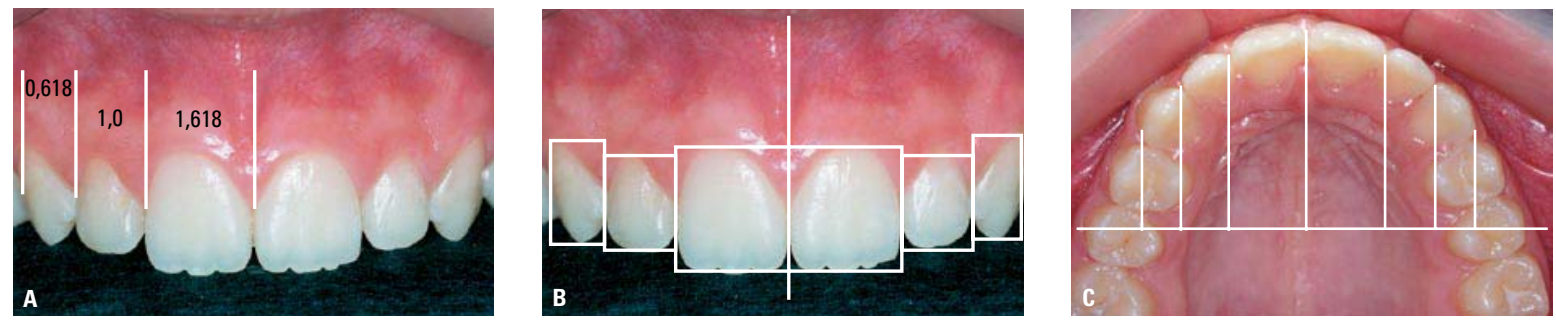

FIGURA 7 - Proporções dentárias.

espontâneo) inicia-se com maior elevação tanto do lábio como do sulco nasolabial, sob a ação de três grupos musculares: o elevador do lábio superior, com origem na região infra-orbital, o músculo zigomático maior e as fibras superiores do bucinador ${ }^{62}$. A aparência de olhos semicerrados deve acompanhar o estágio final do sorriso e representa a contração da musculatura periocular (músculos orbiculares dos olhos) para apoiar a elevação máxima do lábio superior, através da prega nasolabial ${ }^{55}$. $\mathrm{O}$ olhar semicerrado que acompanha o sorriso máximo é um gatilho muscular da face que ativa os centros cerebrais na região temporal anterior, que regula a produção das emoções agradáveis. Assim, sem esta ação final de semicerramento dos olhos, o sorriso perceptivel de felicidade provavelmente é um falso sorriso, sem alegria, da pessoa que está sorrindo (EKMAN, DAVIDSON, FRIESEN apud S. PECK, L. PECK, KATAJA ${ }^{54}$ ).

O estímulo do sorriso é um problema, uma vez que o que é engraçado para um, pode não ser para outro. Recomenda-se, apesar de possíveis questionamentos, a pronuncia da letra " $i$ ", de uma maneira desinibida e exagerada. Dessa forma, pode-se obter a elevação máxima do lábio superior ${ }^{50}$. O registro do sorriso é outro problema. O ideal é que sejam feitos registros estáticos (fotografias) e dinâmicos (filmagem). Nos registros estáticos, a obtenção de imagens deve incluir enquadramentos aproximados nos planos frontal, sagital e oblíquo. Nos registros dinâmicos, a filmagem deve ser gravada e repassada para um computador e a melhor imagem escolhida ${ }^{65,66}$. Na avaliação do sorriso, deve ser dada preferência ao sorriso de elevação máxima do lábio superior (sorriso espontâneo). Tal escolha baseia-se na premissa de que o sorriso social ou voluntário pode não corresponder à realidade, por se tratar de uma expressão aprendida e voluntária. Desse modo, quando solicitados, os pacientes podem "criar" o sorriso que lhe pareça mais atraente ${ }^{59}$.

Em geral, é a forma do lábio inferior e as bordas incisais dos dentes anteriores superiores e inferiores que criam um arranjo agradável ou desagradável do sorriso $^{65}$. O importante é que o plano incisal superior e a forma do lábio inferior, durante o sorriso, mantenham uma relação harmoniosa ${ }^{33,72}$. Essa harmonia é representada pelo paralelismo do arco formado pelas bordas incisais e oclusais dos dentes superiores com a borda superior do lábio inferior (Fig. 8).

Essa configuração varia com a idade. Conforme a idade avança, a forma de "prato fundo" vai se alterando, dando lugar a uma nova forma de "prato raso" ou de "prato fundo invertido". Isto é, a direção das bordas incisais é uma linha reta ou uma curva. $\mathrm{O}$ desgaste das bordas incisais, com o tempo, cria essas novas formas. O conhecimento dessas características cria a possibilidade de rejuvenescer ou envelhecer o sorriso. A alteração das "formas do prato" possibilitará esse efeito (Fig. 12).

\section{Proporções dentárias}

Teoremas matemáticos, tal como a "proporção áurea" e a "percentagem áurea" têm sido propostos na determinação dos chamados espaços mésio-distais ${ }^{40,42}$. Embora a proporção áurea seja um 
interessante objetivo a ser alcançado, nem sempre os pacientes apresentam essa proporção ${ }^{57}$. Nesses casos, o diagrama dentário serve para individualizar cada caso. Isto é, o resultado final deve proporcionar uma relação harmoniosa na visibilidade dos dentes anteriores. $\mathrm{Na}$ vista frontal, a visibilidade dos dentes deve ser decrescente, a partir dos incisivos centrais (Fig. 7).

\section{UTILIZAÇÃO DO DIAGRAMA DE REFERÊN- CIAS ESTÉTICAS DENTÁRIAS (DRED)}

\section{Fechamento de diastemas}

O fechamento de diastemas pode ser feito de três formas: com auxílio da Ortodontia, com preenchimento de materiais restauradores diretos (resina composta) ou indiretos (facetas de porcelana, coroas protéticas) ou ambas as opções (Ortodontia e Cosmética). Nos consultórios clínicos, os espaços entre os incisivos superiores costumam ser preenchidos, em muitos casos, por materiais restauradores diretos ou indiretos, quando o tratamento ortodôntico é rejeitado. Em outras situações, mesmo sendo um pequeno espaço, o paciente só aceita o tratamento ortodôntico. No entanto, em alguns casos, os espaços entre os dentes são muito grandes e/ou existe uma discrepância de tamanho entre os dentes superiores e inferiores (discrepância de Bolton) $)^{8,9}$, havendo a necessidade da integração entre as especialidades ${ }^{12,13,30}$.

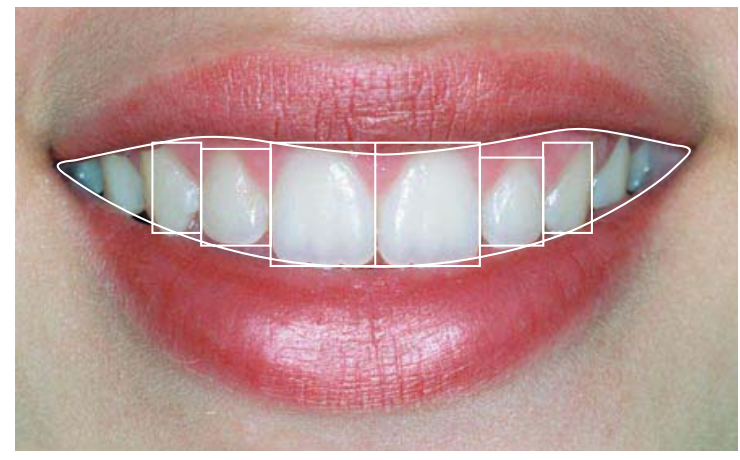

FIGURA 8 - Linhas do sorriso.
A Ortodontia será a responsável pela distribuição e diminuição dos espaços e a Dentística pelo fechamento completo com material restaurador. Nessa situação, o tratamento ortodôntico deve distribuir os diastemas, de forma que os maiores espaços fiquem sempre para distal do dentes. Assim, tira-se proveito do efeito paralax. Explicando melhor, apesar de termos dois objetos do mesmo tamanho, o que está mais próximo aparenta ser maior, apesar de serem iguais (Fig. 9).

O reposicionamento deve ser feito tomando como referência o Diagrama de Referências Estéticas Dentárias. Seguindo os parâmetros estéticos do DRED, a visualização do correto posicionamento dos dentes fica bem simplificada. Embora, o reposicionamento dos dentes no sentido mésio-distal seja o maior objetivo nos tratamentos de diastemas, a acomodação concomitante desses no DRED acarretará obrigatoriamente no alcance dos parâmetros estéticos. No caso apresentado, o diagrama próprio do paciente apresentava um arranjo desarmonioso, que não seguia os padrões de referências estéticas. A utilização do DRED como parâmetro a ser seguido possibilitou o correto posicionamento ortodôntico dos dentes, assim como serviu de referência para a execução das restaurações estéticas e da cirurgia periodontal para a correção do limite do contorno gengival. Os dentes foram movimentados com o intuito da redistribuição dos espaços e, conforme eram posicionados corretamente, faziam-se

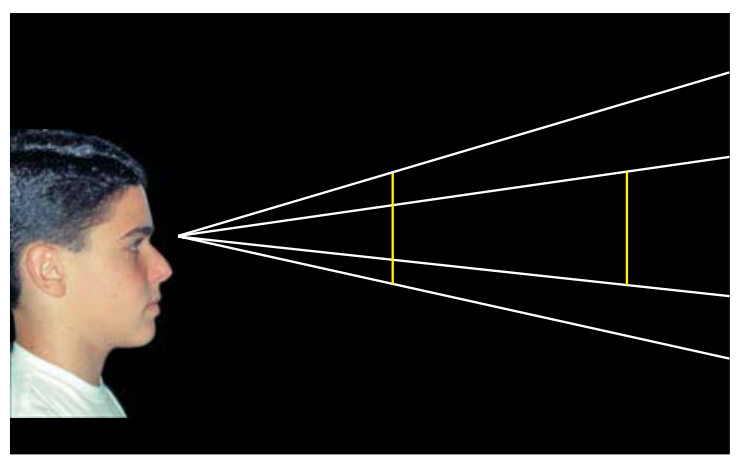

FIGURA 9 - Efeito paralax (llusão de óptica). 
os acréscimos de resina. Esses acréscimos eram feitos de forma provisória, tornando mais fácil o posicionamento dos dentes e, quando necessário, era acrescentado ou desgastado. Antes da remoção do aparelho foi realizada a cirurgia periodontal estética para remoção de gengiva hiperplasiada. Como já foi dito, em todos esses procedimentos tomou-se como referência o DRED (Fig. 10).

No caso apresentado, o aumento da largura dos dentes com restaurações foi feito durante o tratamento, devido à impossibilidade de restaurá-los no pré-tratamento ortodôntico. No entanto, sempre que for possível, o ideal é que os dentes que necessitam de preparo cosmético sejam manipulados antes do tratamento ortodôntico. Isto facilita o reposicionamento dos dentes, pois o tamanho final de cada dente será alcançado antes deles serem movimentados e o seu posicionamento será o definitivo ao final do tratamento ortodôntico.

\section{Sorriso invertido}

Como foi dito anteriormente, as bordas incisais dos dentes ântero-superiores devem criar uma forma de "prato fundo", onde os incisivos centrais se posicionam mais inferiormente aos incisivos laterais e caninos, guardando uma relação de paralelismo com o lábio inferior. Quando as bordas dos incisivos centrais se posicionam mais superiormente do que as incisais dos incisivos laterais, cria-se o sorriso invertido (Fig. 11).

Essa situação é bastante crítica do ponto de vista estético, visto que ocorre uma falta de paralelismo entre as bordas incisais e o lábio inferior; não formando, assim, o chamado arco do sorriso ${ }^{65}$ (Fig. 12).

No caso apresentado, além do sorriso invertido, outros fatores que contribuíam para alterar a estética bucal eram a pouca exposição dos incisivos superiores (sorriso baixo), a inclinação exagerada
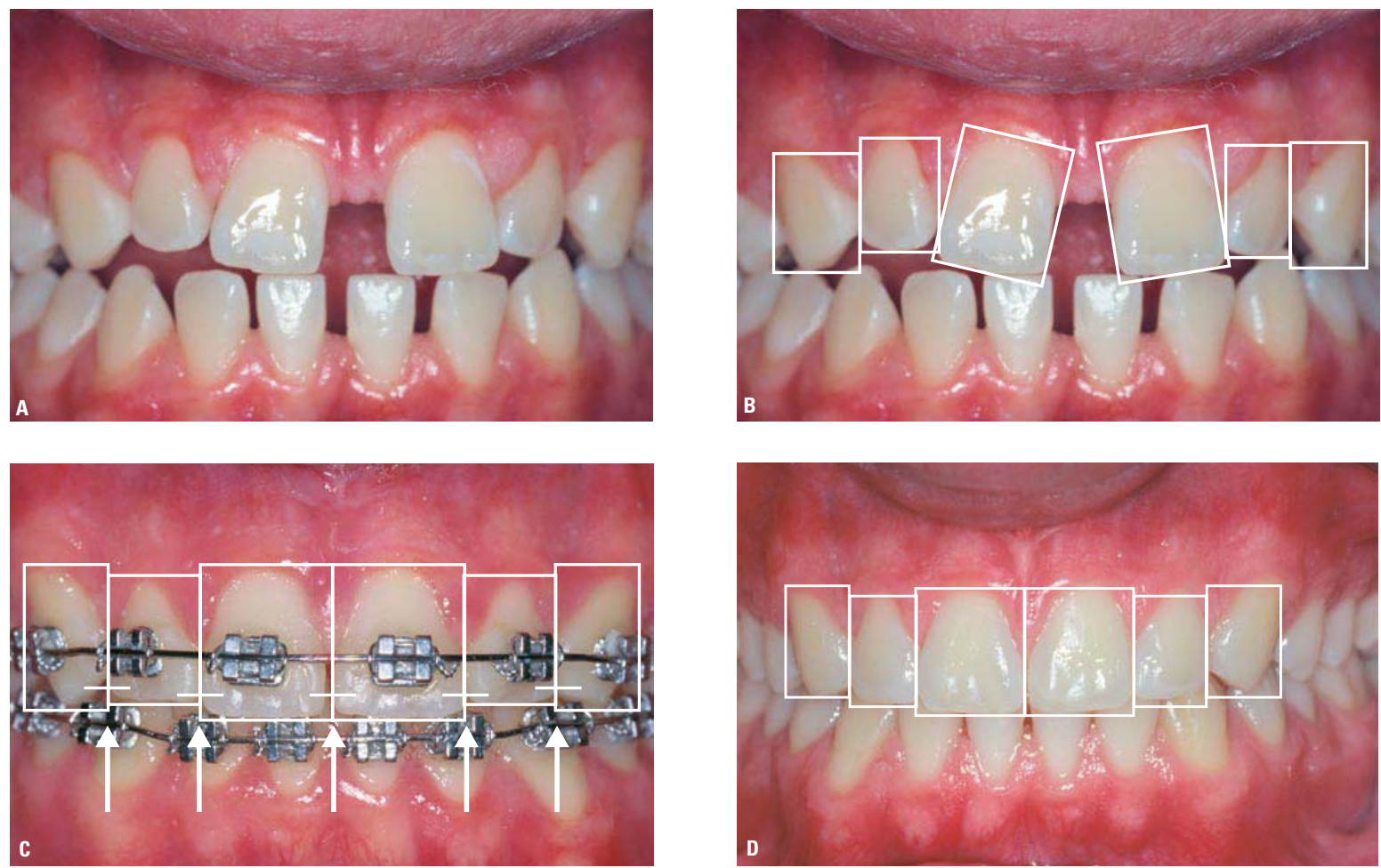

FIGURA 10 - A, B) Dentes estreitos com grandes diastemas e sem encaixe no DRED. C) Restaurações provisórias feitas nos dentes anteriores, durante o tratamento ortodôntico, onde os maiores incrementos de resina composta foram feitos nas superfícies distais. D) Finalização do tratamento ortodôntico e reabilitador e a utilização do DRED. Restaurações de resinas compostas feitas pelo Dr. Dickson Martins da Fonseca. Cirurgia periodontal estética feita pela Dra. Keila Meira. 
para vestibular desses dentes e as suas alterações de cores.

Embora a melhor maneira para se observar a inclinação de incisivos superiores seja através de uma visão sagital ou oblíqua, também é possivel avaliar essa inclinação utilizando o DRED com vista frontal. Quando os incisivos superiores inclinam para vestibular, fazem uma intrusão relativa de sua borda incisal, diminuindo a quantidade de coroa clínica visualizada no sorriso. Esse efeito agrava a percepção do sorriso invertido, sendo notado na confecção do diagrama. Para se corrigir essa situação de inclinação dos incisivos, a Ortodontia terá de contar com os recursos e opções disponíveis. Para se corrigir incisivos inclinados para vestibular, terá que ser avaliado qual a melhor maneira para desincliná-los, levando em consideração as repercussões que a retração de incisivos irá causar no tegumento. Em alguns casos, apenas o desgaste de dentes com a posterior retração é suficiente para corrigir essas inclinações de coroas para vestibular, em outros, aonde a biprotrusão é acentuada, será necessária a extração de dentes. Essa ultima opção foi a adotada nesse caso (Fig. 13).

Quando tentamos corrigir a posição de dentes anteriores, podemos influir no posicionamento desses dentes nos três planos do espaço. O objetivo de buscar o enquadramento no DRED deve levar em consideração o relacionamento dos dentes anteriores com os posteriores e de todo o arco dentário com as bases ósseas. A possibilidade de

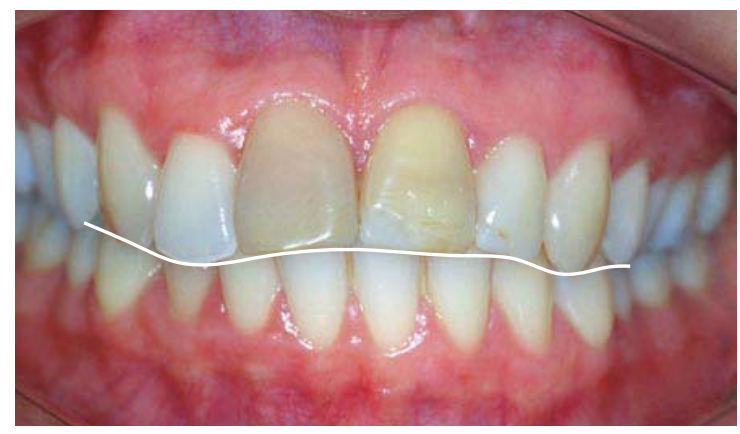

FIGURA 11 - Sorriso invertido. extrusão e intrusão, retração e projeção, mesialização e distalização será considerada dentro de um contexto do correto posicionamento entre os dentes, suas bases ósseas e o seu padrão morfogenético. No presente caso clínico, foi dada uma maior importância ao posicionamento vertical dos dentes anteriores, para que repercutisse no posicionamento das bordas incisais. Como os incisivos centrais superiores não eram mostrados por completo, a harmonia entre bordas incisais e lábio inferior passava a ser um fator determinante para uma melhor aparência do sorriso. Esse é um fator importante a ser levado em consideração, visto que a obtenção de resultados estéticos satisfatórios em pacientes de sorriso baixo é mais difícil do que naqueles de sorriso alto e médio. A alteração dos fatores que contribuem para um sorriso baixo, como a contração labial, tamanho do lábio superior e dimensão vertical da maxila, requer envolvimento cirúrgico e nem sempre o paciente deseja essa opção, além da dificuldade de previsibilidade e contenção dos resultados ${ }^{58}$.

O posicionamento das bordas incisais em forma de "prato fundo" proporcionou a agradabilidade do conjunto dentes/lábios. No entanto, apenas com o nivelamento ortodôntico não seria possível resolver todos os problemas estéticos, uma vez que as colorações dos incisivos centrais superiores estavam alteradas. Nesse caso, foram confeccionadas facetas de porcelanas nos incisivos superiores. Também poderia utilizar-se restaurações com-

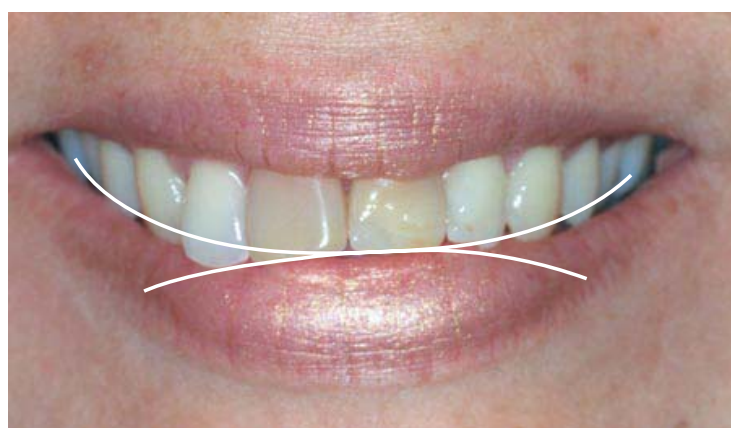

FIGURA 12 - Ausência de paralelismo entre 0 arco dentário superior e a borda superior do lábio inferior. 

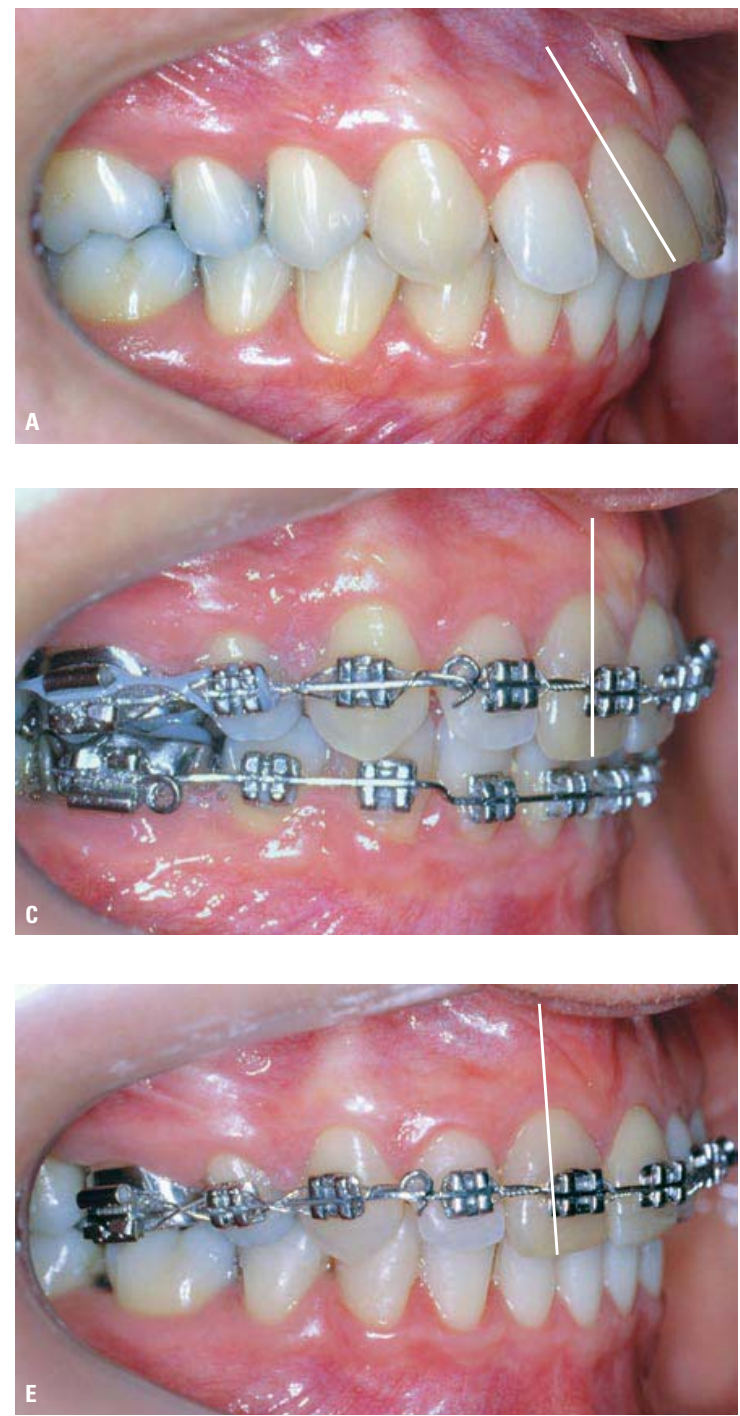

FIGURA 13 - A, B) Inclinação acentuada para vestibular das coroas dos incisivos superiores pré-tratamento. C, D) Correção da inclinação dos incisivos através de extrações de pré-molares e posterior retração. E, F) Leve descompensação do excesso de inclinação para lingual das coroas dos incisivos superiores, que ocorreu após a retração dos incisivos.

postas diretas, ao invés de facetas de porcelana, para restaurar a coloração e a forma dos incisivos. Nesses casos, mais importante do que se ater ao material utilizado, deve-se levar em consideração a técnica, o conhecimento, os conceitos e a capacidade do profissional (Fig. 14).

Como já foi dito, solucionar problemas estéticos em pacientes de sorriso baixo não é tarefa fácil. Mesmo quando se conta com cirurgia, os resultados em longo prazo não são os mais otimistas ${ }^{58}$.
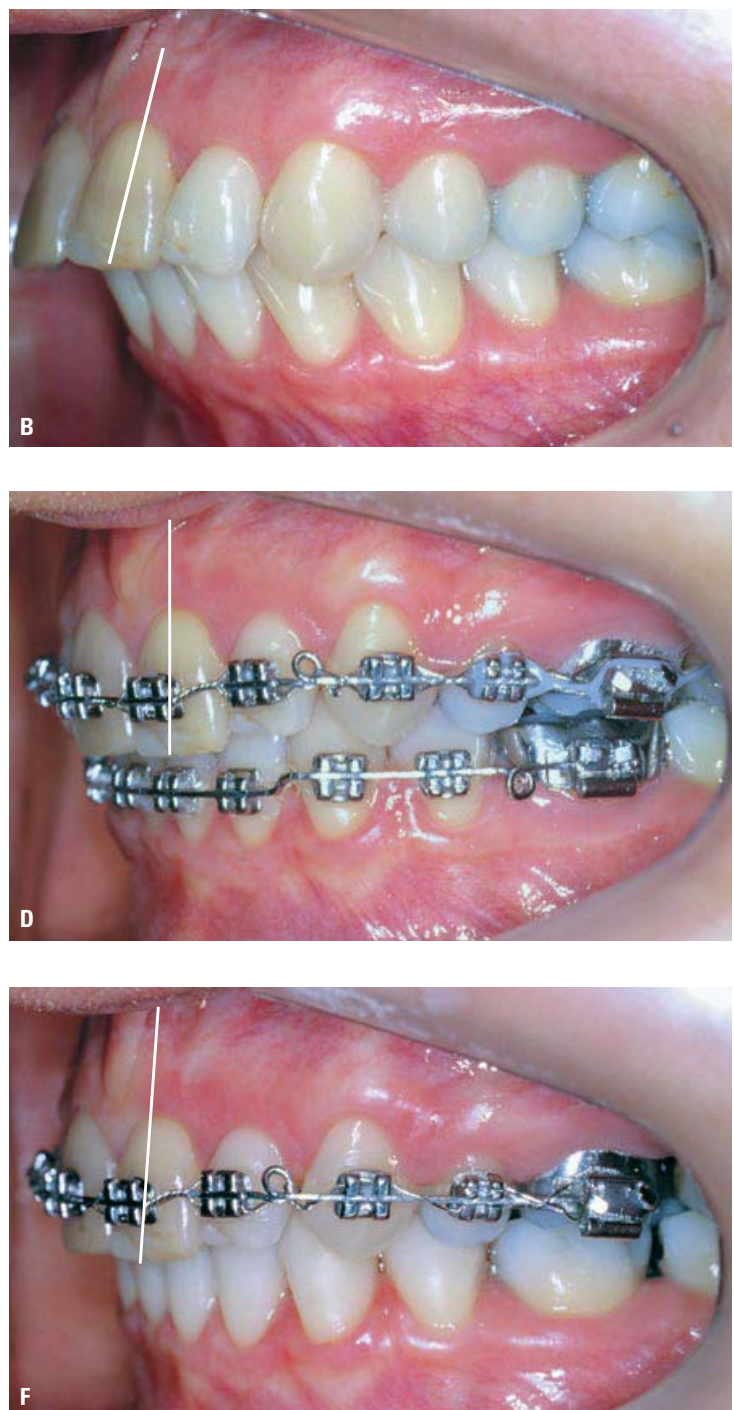

Sendo assim, a utilização do DRED servirá com uma boa ferramenta para se obter os melhores resultados estéticos, principalmente quando o seu uso estiver associado ao Diagrama de Referências Estéticas Faciais (DREF), que será discutido a seguir.

\section{DIAGRAMA DE REFERÊNCIAS ESTÉTICAS FACIAIS (DREF)}

Os Diagramas de Referências Estéticas Fa- 

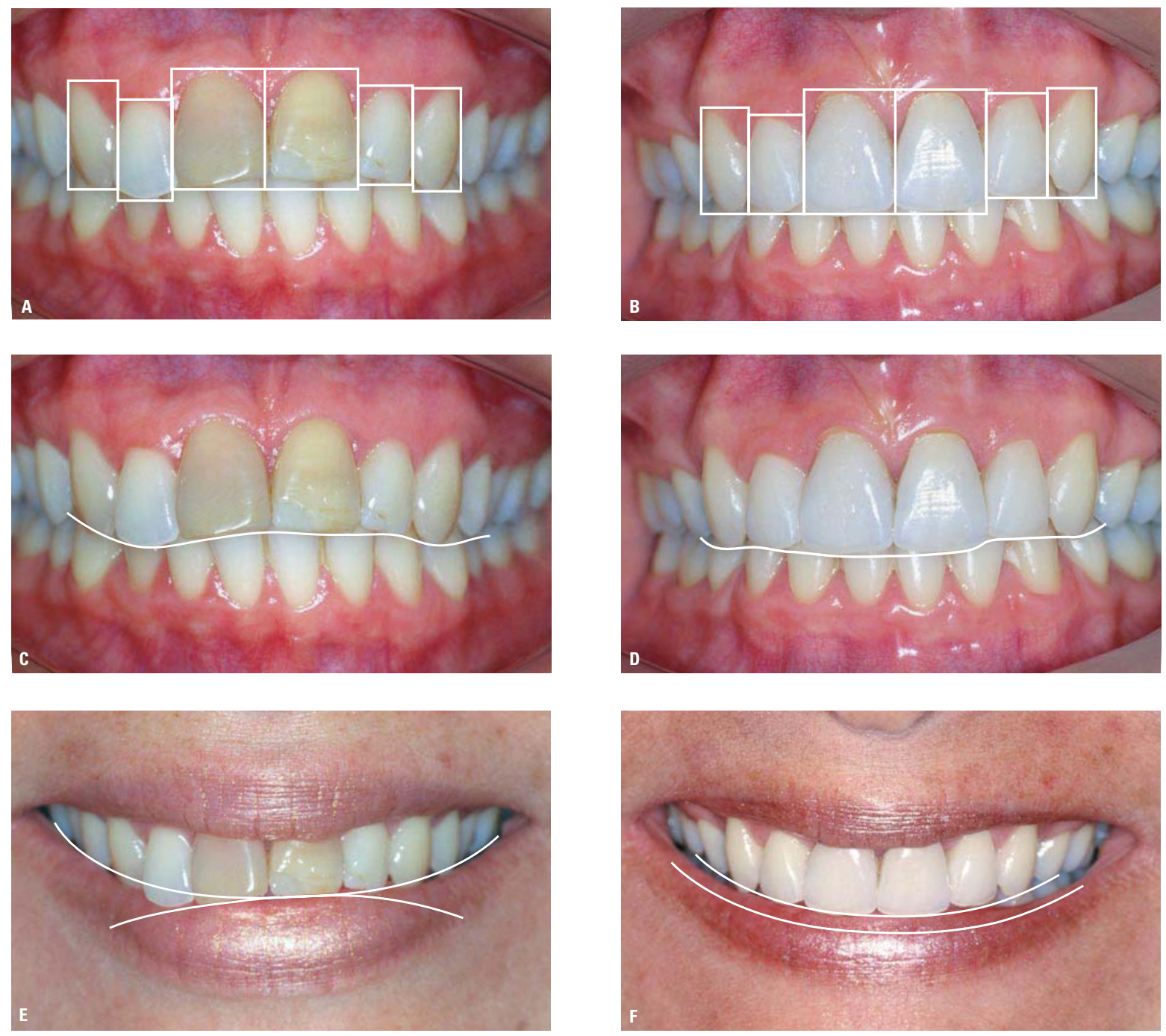

FIGURA 14 - A, B) Diagramas de Referências Estéticas Dentárias (DRED) pré e pós-tratamento. C, D) Reposicionamento ortodôntico dos dentes anteriores e colocação de facetas de porcelana nos incisivos superiores, criando a "forma de prato fundo" e corrigindo as alterações de cores. E, F) Obtenção do paralelismo entre 0 arco do sorriso dentário e o lábio inferior. Tratamento restaurador dos incisivos superiores realizado pela Dra. Nia Torquato e pelo TPD Lécio Gomes.

ciais, em conjunto com o Diagrama de Referências Estéticas Dentárias, terão o intuito de prover uma avaliação estética odontológica global, simplificada e individualizada de cada paciente. A simplicidade dos diagramas é intencional, uma vez que seria interessante que todas as especialidades odontológicas pudessem tirar proveito das informações obtidas nesses diagramas, que não precisam de informações numéricas para serem interpretados. A facilidade de interpretação dos diagramas deve-se a conceitos muito antigos, pois desde os tempos das dinastias egípcias do Reino Antigo (2.600 - 2.000 a.c.) já se tinha atenção às proporções faciais ${ }^{53}$. Deve ficar claro que, embora os Diagramas de Referências Estéticas Faciais sirvam como análises faciais subjetivas simplificadas, não têm a intenção e a pretensão de serem classificados como tal, nem substituir qualquer outro tipo de análise ortodôntica, principalmente a tradicional análise cefalométrica, mas sim de 

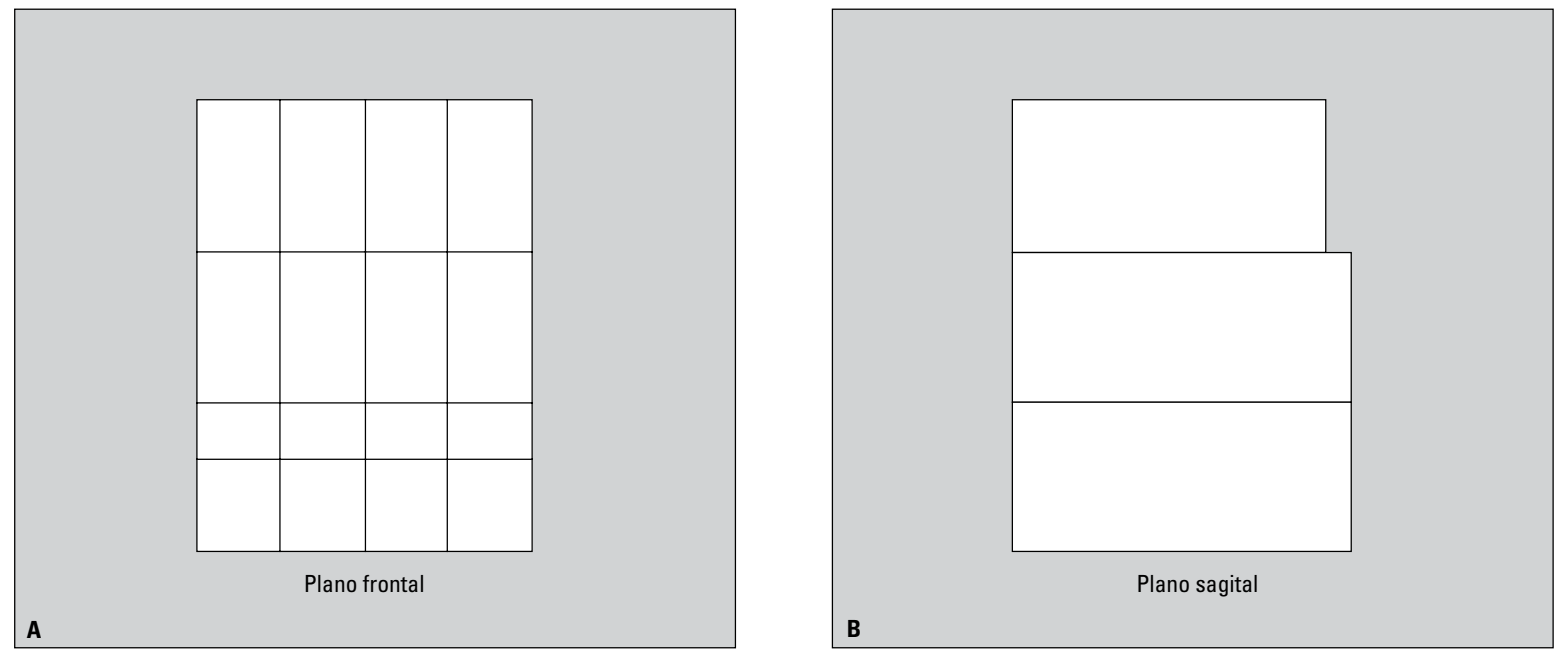

FIGURA 15 - Diagramas de Referências Estéticas Faciais (DREF) - vista frontal e sagital.

servirem como instrumentos de referência para complementar e auxiliar no diagnóstico e planejamento de casos clínicos, promovendo e facilitando a integração entre todas as especialidades envolvidas com a Odontologia Estética.

A estética facial é um dos principais objetivos ortodônticos ${ }^{7,10}$. O desejo de melhorar a estética dentofacial é uma das razões pelas quais os pacientes procuram tratamento ${ }^{34}$. Com esse propósito, a Ortodontia tem a necessidade de avaliar, diagnosticar e tratar os pacientes com problemas dentofaciais. No entanto, considerar as suas limitações terapêuticas e, principalmente, avaliar as suas possibilidades de atuação nos diversos padrões morfogenéticos, parece ser uma atitude correta a ser tomada ${ }^{15}$. Observar as informações obtidas em uma análise morfológica de tecido mole e saber acatar as limitações que essas informações oferecem, parece ser um preceito universal para se obter os melhores resultados de um tratamento. Daí a importância de uma análise morfológica bem feita, que possa oferecer ferramentas suficientes para a distinção de problemas. Mas como fazer essa análise? Diagramas de Referências Estéticas Faciais (DREF) ajudam a definir um padrão de normalidade das proporções faciais em norma frontal e sagital e servem para dar uma noção simplificada das relações entre as diversas estruturas faciais, assim como suas proporções. A utilização dos diagramas como gabaritos das proporções faciais facilita ainda o entendimento entre as diversas especialidades odontológicas, sem a necessidade de memorização de tabelas, números e padrões pré-determinados. Afinal, o conceito de beleza facial depende de vários fatores, como a opinião pessoal, a região em que o indivíduo mora, a mídia e a moda; todos eles servindo para influenciar a percepção de estética $^{31}$. Assim, as medidas tornam-se válidas para uma determinada população, em um determinado tempo ${ }^{5}$. O julgamento clínico nunca pode ser substituído por qualquer dogma estabelecido com base em valores médios, porque estes, quando muito, indicam apenas uma tendência ${ }^{52}$. Em outras palavras, não se deve utilizar um único conjunto de valores como padrão universal na obtenção de resultados esteticamente prescritos, sem a devida consideração das variações faciais, antecedentes étnicos, traços familiares e preferências pessoais dos indivíduos ${ }^{39}$.

É importante observar que diagramas que se prestam a facilitar a visualização das estruturas faciais conseguem oferecer informações, embora simples, importantes, para que sejam feitas as avaliações das estruturas faciais e suas características estéticas. A utilização do DREF é feita em fotografias, que são de baixo custo e não expõem 
o paciente à radiação nociva ${ }^{28}$. Além disso, com o advento da fotografia digital, a possibilidade de se analisar o registro fotográfico diretamente no computador facilitou bastante o estudo dos casos clínicos. Entretanto, muitos trabalhos que utilizam fotografias têm seu valor científico reduzido pela falta de padronização na obtenção dessas ${ }^{73}$. Na utilização do DREF recomenda-se utilizar a Posição Natural da Cabeça (PNC) para o registro fotográfico, pois a PNC é uma posição com boa acurácia reprodutiva ${ }^{21,43,56}$.

Essa posição pode ser determinada pela sensação de equilíbrio do paciente, auxiliada pelo uso de um espelho, onde o paciente olha diretamente para os seus olhos, e estimada pelo próprio profissional $^{19,22,44}$. Qualquer tipo de rotação da cabeça na tomada fotográfica deve ser evitada, pois na foto de perfil as rotações anteriores simulam prognatismos e as posteriores podem sugerir retrognatismos. $\mathrm{Na}$ vista frontal, rotações laterais aparentam assimetrias ${ }^{3,20}$. Embora a distância das tomadas fotográficas deva ser padronizada, a avaliação do DREF não será alterada pela diferença de distâncias, pois o DREF não utiliza medidas lineares e sim análises de proporções.

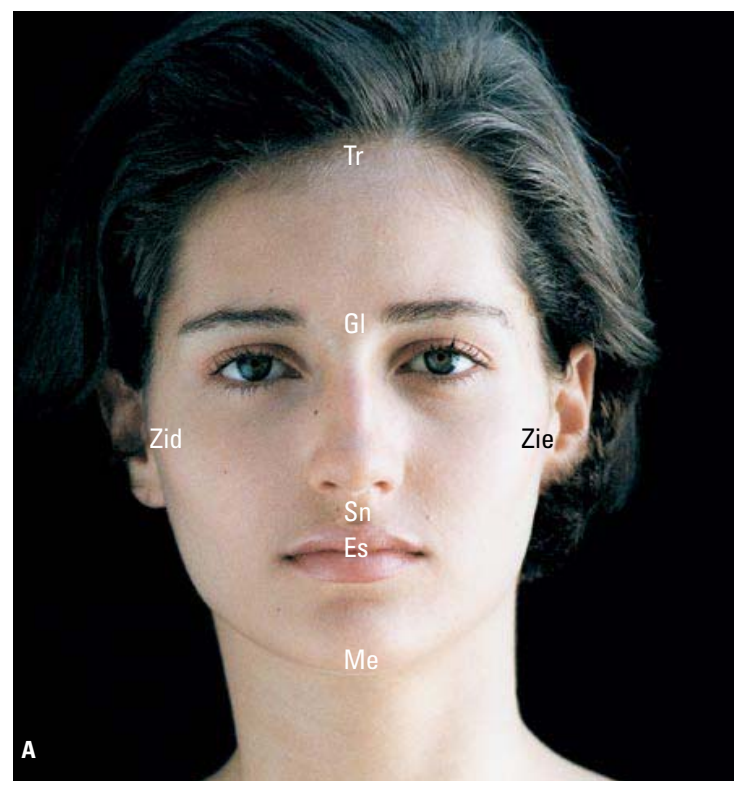

Os Diagramas de Referências Estéticas Faciais (DREF) serão feitos em norma frontal e sagital e poderão visualizar as seguintes características (Fig.15):

1) Simetria;

2) Proporção e altura dos terços frontais;

2.1) Proporção e altura das partes do terço inferior da face (lábio superior, lábio inferior e mento);

3) Proporção, altura e posicionamento dos terços sagitais;

3.1) Proporção e tamanho da linha mento-pescoço.

Os pontos fotométricos que serão utilizados para se montar os Diagramas de Referências Faciais (DREF) serão os seguintes (Fig. 16):

- Zi' - Zígio direito (Zid) e esquerdo (Zie): ponto mais lateral do arco zigomático do lado direito e esquerdo.

- Tr' - Tríquio: ponto mais superior no plano sagital da fronte. Este ponto é limitado pela linha do cabelo.

- Gl' - Glabela tegumentar: ponto mais anterior no plano sagital da fronte.

- Sn - Subnasal: ponto localizado na confluên-

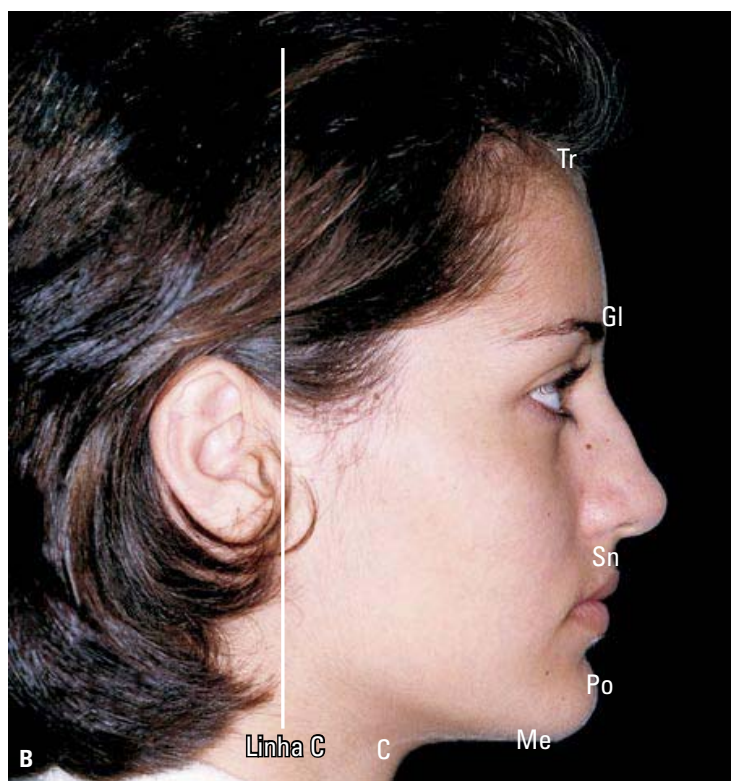

FIGURA 16 - A) Pontos de referência fotométricos em norma frontal. B) Pontos de referência fotométricos em norma lateral (foto Dudu Medeiros). 

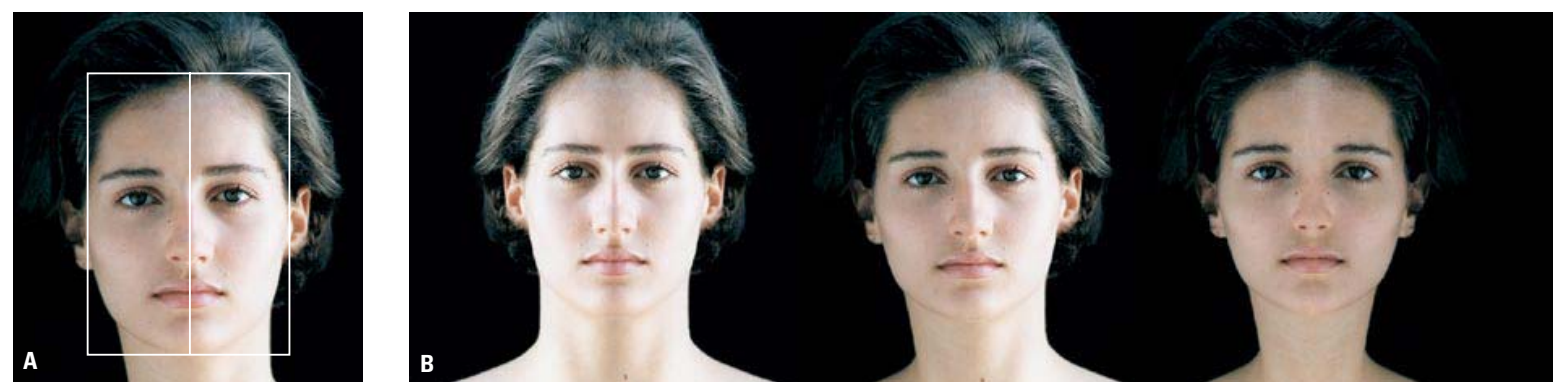

FIGURA 17 - A) Diagrama de Referência Estética Facial (DREF) para avaliar a simetria. B) Colagem fotográfica dos lados direito/direito invertido, fotografia natural, colagem fotográfica dos lados esquerdo/esquerdo invertido. Note que a face mais agradável é a real, que possui alguma assimetria (foto Dudu Medeiros).

cia entre a margem inferior da columela nasal e o lábio superior.

- Me' - Mentoniano Mole: ponto mais inferior do contorno do mento.

- Es - Estômio: ponto localizado na união do lábio superior com o inferior.

- Pg' - Pogônio Tecido Mole: ponto mais proeminente do contorno do mento mole.

- C (cervical): ponto de união entre a base inferior da mandíbula e o pescoço.

- Linha C: linha que tangencia a região mais anterior do ouvido externo, paralela à linha vertical verdadeira.

\section{Simetria}

A simetria bilateral é um padrão existente na beleza facial. Traçando-se uma linha imaginária na direção vertical (linha vertical verdadeira), cruzando perpendicularmente à linha da visão e dividindo a face em lado direito e esquerdo, obtêm-se, em faces harmoniosas, duas metades simétricas. A absoluta simetria não é o que se espera entre as duas metades, mas sim o equilíbrio ${ }^{51}$. Por isso, pequenas diferenças entre o lado direito e esquerdo são esperadas e consideradas normais ${ }^{27}$ (Fig. 17).

\section{Proporção e posicionamento dos terços frontais}

Em uma vista frontal, a face pode ser dividida em três terços: 1) Terço superior da face; 2) Terço médio e 3) Terço inferior. O balanço geral da face (proporcionalidade vertical) é encontrado quando os três terços possuem aproximadamente o mesmo tamanho na direção vertical. Esses três terços estão dentro de uma variação entre 55 a $65 \mathrm{~mm}$, verticalmente ${ }^{3}$. Embora essas medidas possam servir de referência, na utilização do DREF a percepção de proporcionalidade entre os três terços será sempre mais importante do que qualquer medição (Fig. 18).

\section{Terço superior frontal}

O terço superior está limitado pela linha do cabelo (ponto tríquio - Tr), na parte superior, e pela linha das sobrancelhas (ponto glabela $\mathrm{Gl}^{\prime}$ ), na inferior. Esse terço, por estar limitado com a linha do cabelo, pode sofrer variação, conforme o estilo, posição e quantidade de cabelo, sendo assim o menos preciso dos terços verticais. No entanto, qualquer alteração mais significativa na área frontal pode ser observada e estar associada com alguma síndrome craniofacia ${ }^{25}$. Embora impreciso, o terço superior poderá servir como critério de comparação para os outros dois terços. Explicando melhor, o método visual de avaliação do diagrama, por não usar valores numéricos, e sim comparações, terá no terço superior um parâmetro de comparação para se saber quais dos terços restantes encontram-se fora do padrão. Essa avaliação servirá para facilitar a leitura do problema, uma vez que o terço superior da face é o mais estático dos terços e o primeiro a ter o seu tamanho estabelecido. É evidente que essa comparação só poderá 

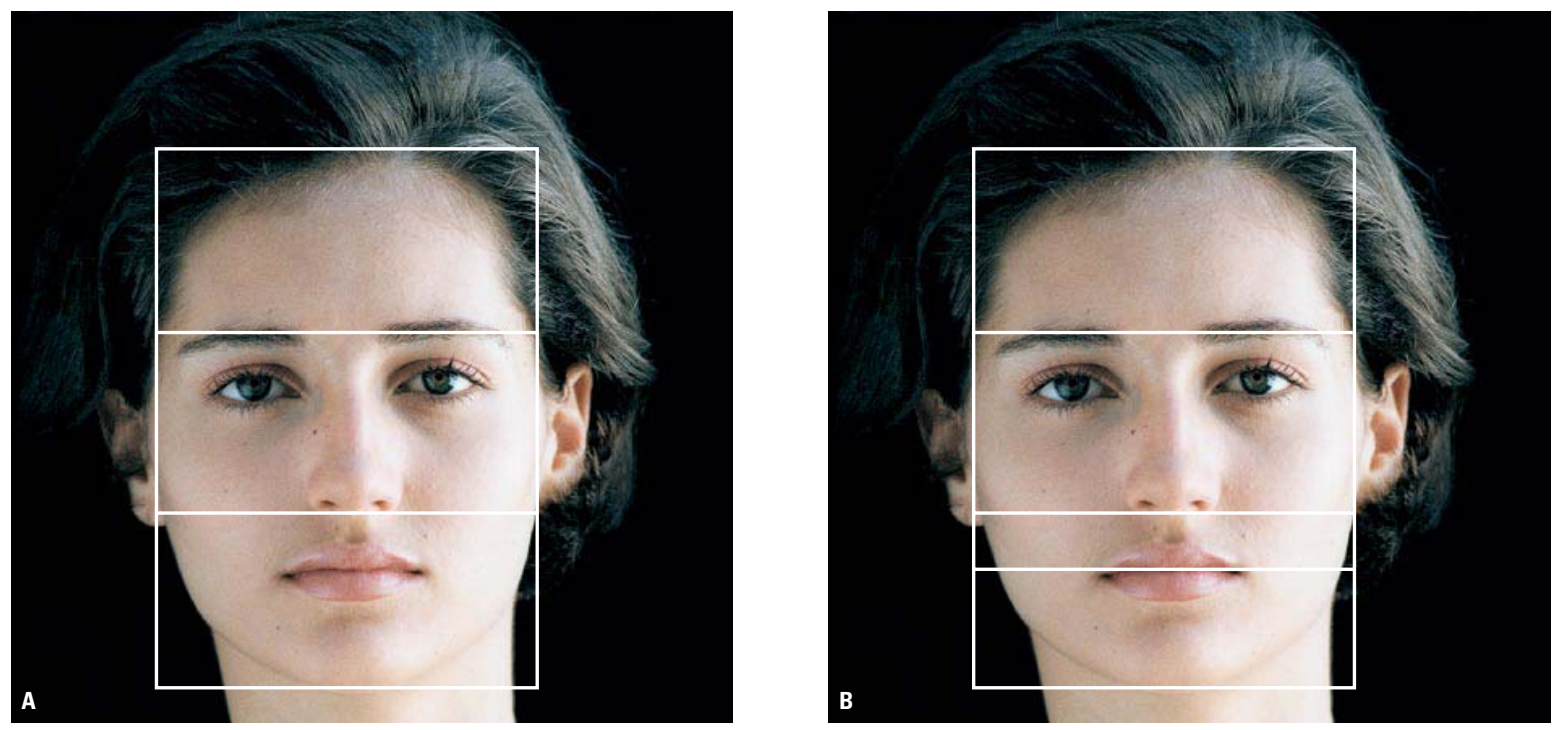

FIGURA 18 - A) Proporções entre os terços faciais - vista frontal. B) Terços faciais e sub-divisão do terço inferior (foto Dudu Medeiros).

ser feita quando o terço superior puder ser facilmente visualizado e apresentar uma boa proporção.

\section{Terço médio frontal}

Os limites do terço médio são dados pelas sobrancelhas e região subnasal. Nesse terço encontram-se os olhos e o nariz. A projeção zigomática e a depressão infraorbitária também podem ser vistas nesse terço. Nessa vista frontal, a proporção ideal da largura da base do nariz é encontrada quando ela é a mesma da distância intercantal. No terço médio teremos a oportunidade de avaliar o desenvolvimento do complexo naso-maxilar. A expressão tegumentar que esse complexo irá imprimir na face dará pistas do seu crescimento e desenvolvimento, influenciando no manejo ortodôntico e no seu prognóstico. A discrepância vertical do terço médio, com relação aos outros terços, por excesso ou deficiência, irá macular a leitura estética da face (Fig. 19).

\section{Terço inferior frontal}

O terço inferior está limitado pela região subnasal e mento. Nas faces com boa estética, o terço inferior é praticamente do mesmo tamanho dos terços superior e médio. Nesse terço encontram-se, além da boca, os sulcos nasogeniano e mentolabial. Com relação à boca, a sua largura deve se aproximar da distância interpupilar. Embora exista a participação da maxila e mandíbula neste terço, é a mandíbula quem terá participação predominante na expressão tegumentar. Como o complexo naso-maxilar faz no terço médio, a mandíbula dará uma impressão na leitura facial que levará a uma perspectiva de conhecimento do crescimento e desenvolvimento do padrão morfogenético. No DREF frontal o terço inferior será sub-dividido, tomando como referência o tamanho vertical do lábio superior [subnasal (Sn) até o estômio (Es)], deixando a outra parte ser preenchida pelo lábio inferior e mento. Essa relação deve guardar uma proporção de $1: 2^{11,38}$. Isto é, o comprimento do lábio superior deverá ser a metade do comprimento do lábio inferior e mento (Fig. 20).

\section{Proporção e posicionamento dos terços sagitais}

Os terços sagitais têm os mesmos limites superiores e inferiores dos terços frontais. No sentido ântero-posterior, os terços superior, médio e inferior são limitados na região posterior por uma linha vertical que tangencia o limite da região an- 

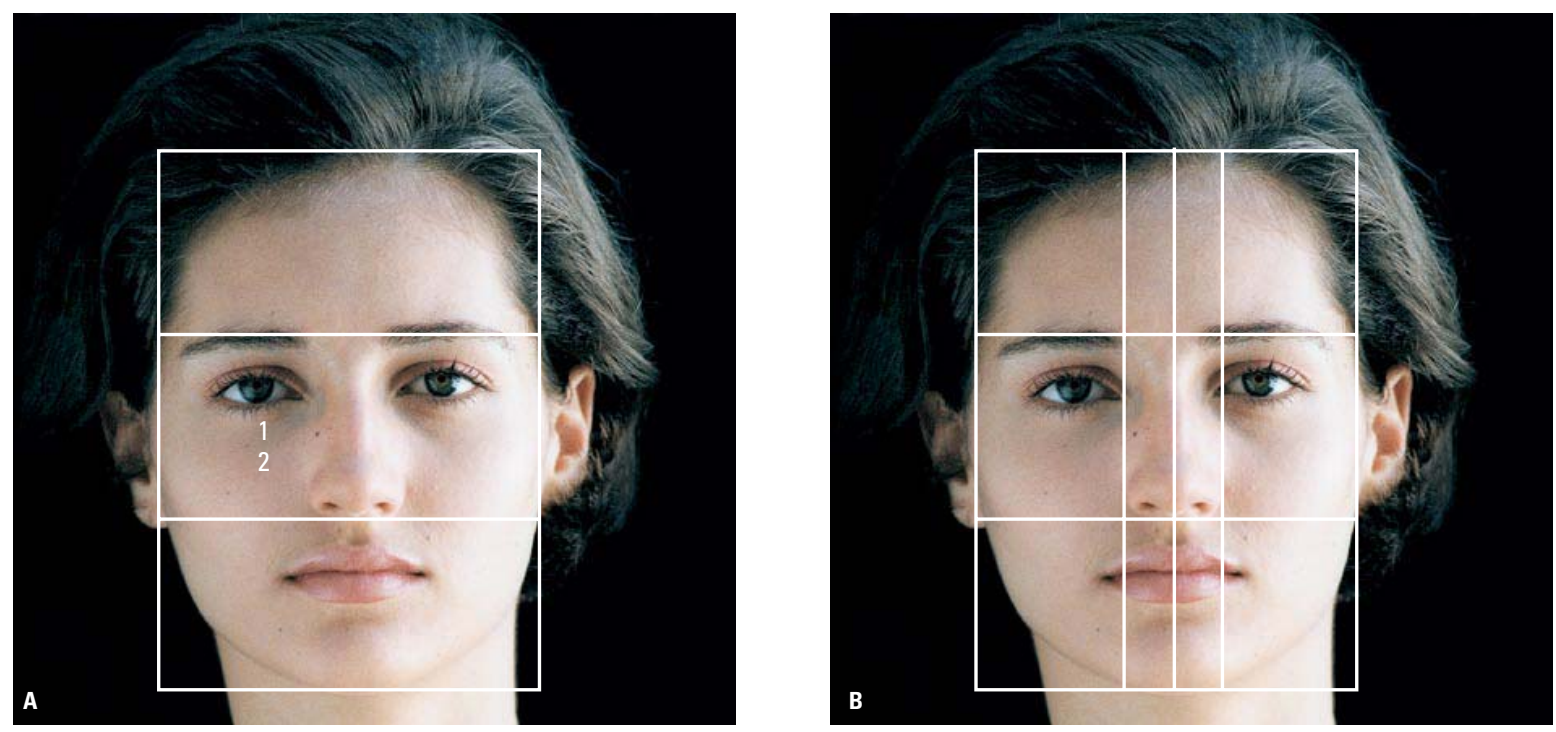

FIGURA 19 - A) 1 - Depressão infraorbitária, 2 - Projeção zigomática. B) Relação entre a largura da base do nariz e a distância intercantal (foto Dudu Medeiros).

terior do ouvido externo (Linha C). Na região anterior, os terços obedecem aos seguintes limites:

- Terço superior: Glabela Tegumentar (Gl');

- Terço médio: Subnasal (Sn);

- Terço inferior: Pogônio Tecido Mole (Pg'). Nesse terço também existe uma divisão hipotética e aproximada entre o corpo e o ramo da mandíbula. Essa divisão é feita através de uma linha que tangencia verticalmente o ponto cervical (C) (Fig. 21).

A relação que esses três terços guardam entre si será considerada ideal quando o terço superior se posicionar posteriormente (mais nos homens do que nas mulheres) aos terços médio e inferior e a relação entre o terço médio e inferior for de equivalência. $O$ posicionamento um pouco mais retruído do terço inferior será considerado normal (convexidade facial), dependendo da idade, gênero e tipo racial. Conforme o padrão esquelético, poderão ocorrer mudanças nas relações espaciais entre os terços, com o aumento da idade ${ }^{48,49,64}$. Na direção vertical, o equilíbrio da face segue o mesmo princípio do plano frontal, ou seja, o três terços com aproximadamente o mesmo tamanho.

O terço inferior será divido em duas partes, sendo que a região anterior terá o seu comprimen- to representado pela linha mento-pescoço. Para medir o comprimento dessa linha não é necessária a utilização de valores numéricos. Esta distância é subjetivamente descrita como normal, longa ou curta $^{4}$. Como já foi dito, no DREF, mais importante que medidas lineares é a visualização das proporções entre as partes dos terços.

Embora as estruturas de lábios e nariz sejam importantes na avaliação estética do perfil facial, o DREF não engloba essas estruturas, mas também não as exclui. A análise subjetiva feita pelos diagramas permite que sejam observadas essas estruturas em norma frontal e o seu relacionamento com as caixas dos diagramas em norma lateral. A intenção do diagrama não é fazer uma análise ortodôntica detalhada, embora reconheça a importância dessas estruturas na avaliação geral da estética do perfil ${ }^{24,68}$. A utilização de análises do perfil facial que oferecem um estudo detalhado de nariz e lábios está indicada para o planejamento de casos ortodônticos e cirúrgicos que requeiram maiores detalhes dessas estruturas ${ }^{11,61,70}$. Como acontece na vista frontal, a depressão infraorbitária, a projeção zigomática e os sulcos nasogeniano e mentolabial também podem ser vistos em norma lateral (Fig. 22). 

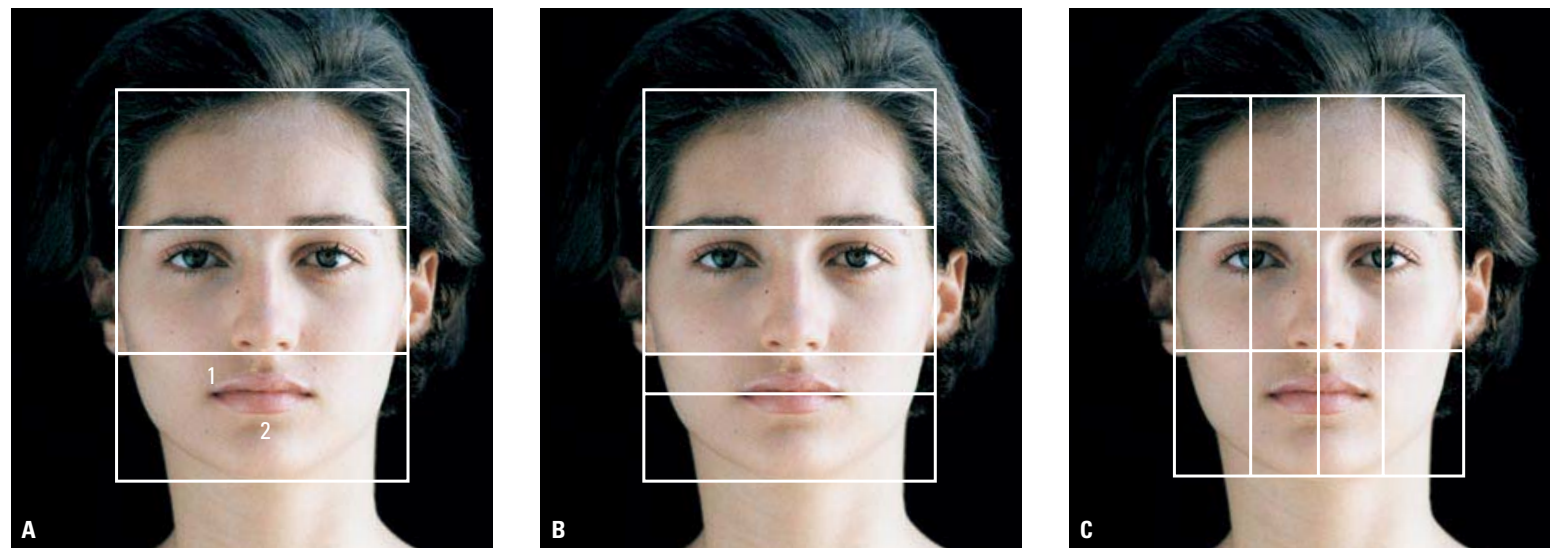

FIGURA 20 - A) 1-Sulco nasogeniano, 2 - Sulco mentolabial. B) No terço inferior o comprimento do lábio superior deverá ser a metade do comprimento do lábio inferior e mento. C) Relação entre a largura da boca e a distância interpupilar (Foto Dudu Medeiros).

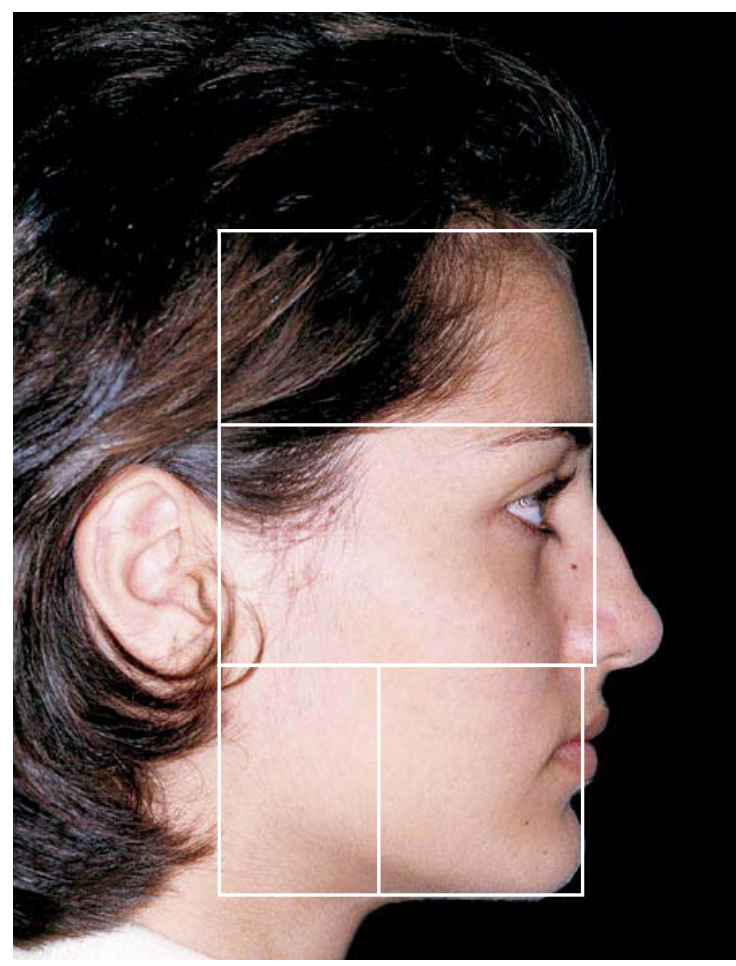

FIGURA 21 - Diagrama de Referências Estéticas Faciais (DREF) - vista sagita (foto Dudu Medeiros).

\section{UTILIZAÇÃO DOS DIAGRAMAS DE REFE- RÊNCIAS ESTÉTICAS FACIAIS (DREF)}

O emprego do conceito de padrão craniofacial, que amplia a classificação das más oclusões para além da relação molar e da posição dos dentes, faci-

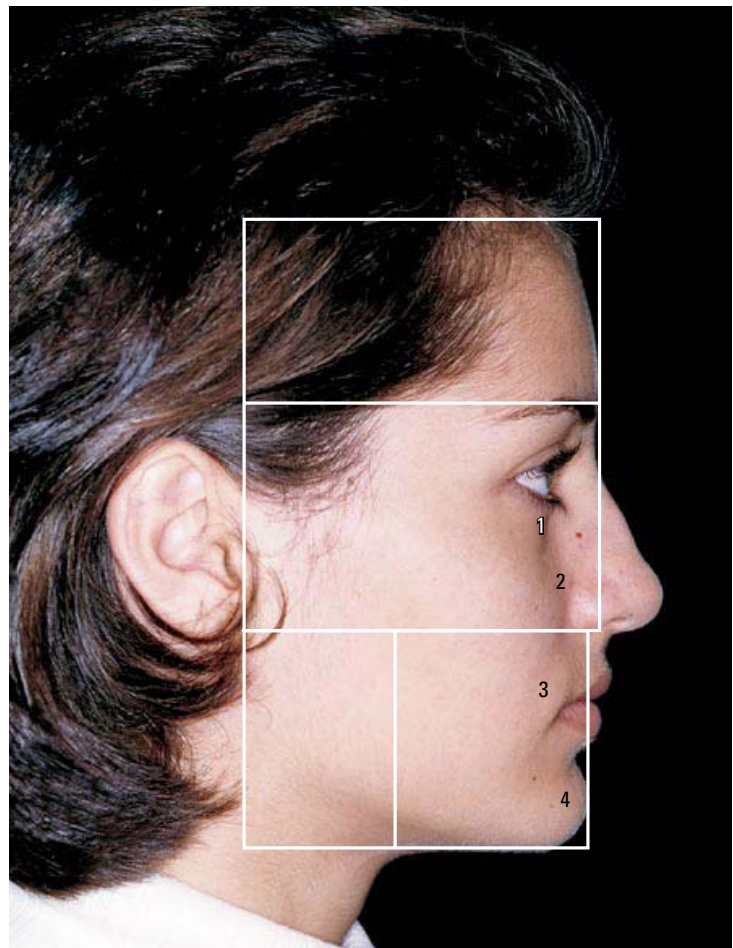

FIGURA 22 - 1) Depressão infraorbitária. 2) Projeção zigomática. 3) Sulco nasogeniano. 4) Sulco mentolabial (foto Dudu Medeiros).

lita bastante o entendimento da morfologia facial. Esse conceito de classificação se baseia no reconhecimento da má oclusão como doença, queé expressa no padrão de crescimento geneticamente instituído e pode ser avaliada em norma frontal e sagital. 


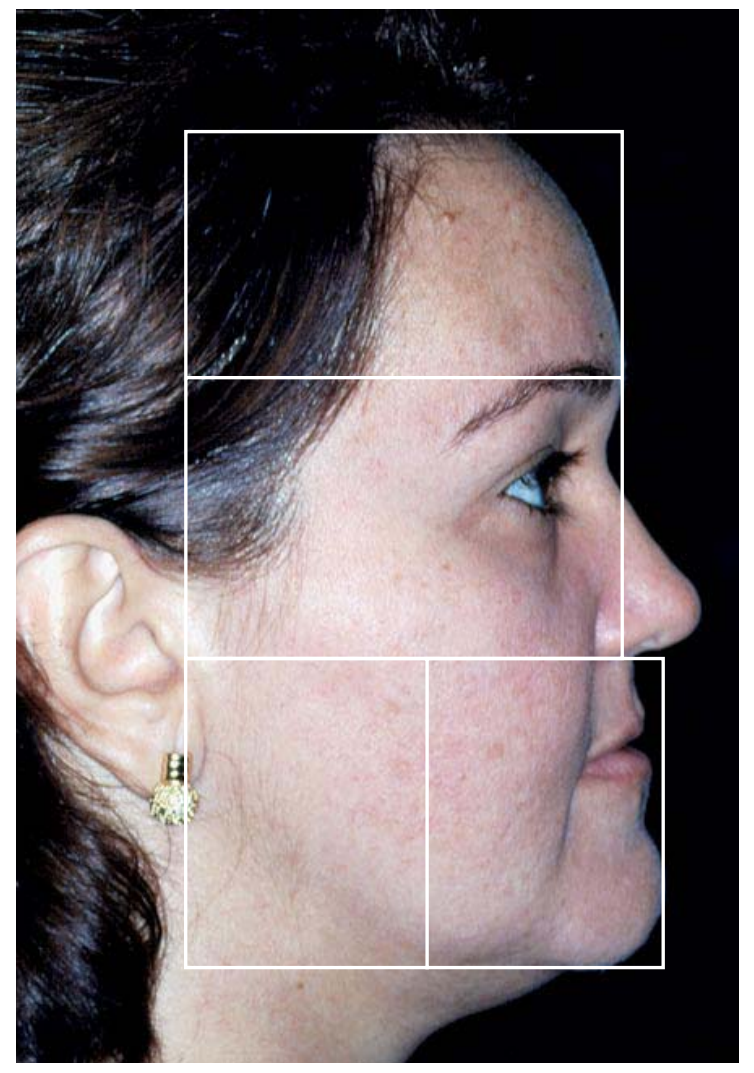

FIGURA 23 - Discrepância entre os terços faciais (norma lateral).

As desproporções entre os terços faciais irão ser responsáveis pela classificação dos pacientes em Padrão I, II, III, face longa e face curta, dependendo do fator primário de desajuste nas relações maxilomandibulares. Cada padrão terá uma característica morfogenética própria, que deverá ser avaliada subjetivamente e que evita, via de regra, uma avaliação por análises numéricas. Dessa forma, Capelozza, o autor desse conceito, prefere uma análise subjetiva à falsa segurança da avaliação numérica ${ }^{15}$. Diante desse dilema, a utilização dos Diagramas de Referências Estéticas Faciais parece se encaixar facilmente nessa perspectiva de avaliação subjetiva, pois utiliza uma comparação intrínseca das proporções faciais, sem a utilização de uma avaliação numérica. Embora Capelozza não tenha utilizado nenhuma análise facial espe-
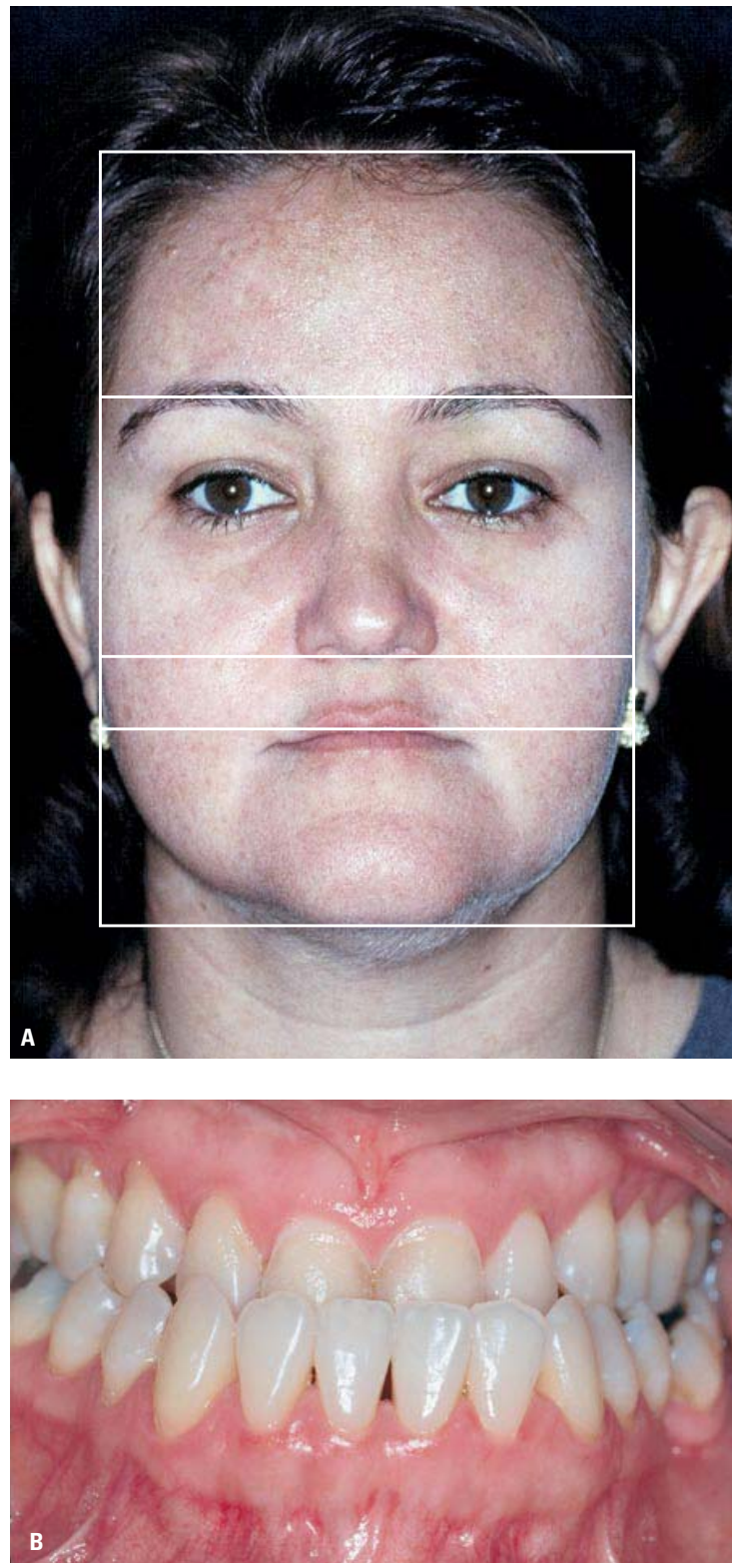

FIGURA 24 - A) Vista frontal da face - pequeno aumento do terço inferior. B) Vista frontal do arco - ausência dos caninos superiores.

cífica para estabelecer a classificação dos padrões, preferindo a comparação entre padrões e o conceito de agradabilidade ${ }^{15,60}$, parece crivel que uma análise morfológica possa ser intrinsecamente feita de uma maneira facilitada e individualizada pelo DREF. 

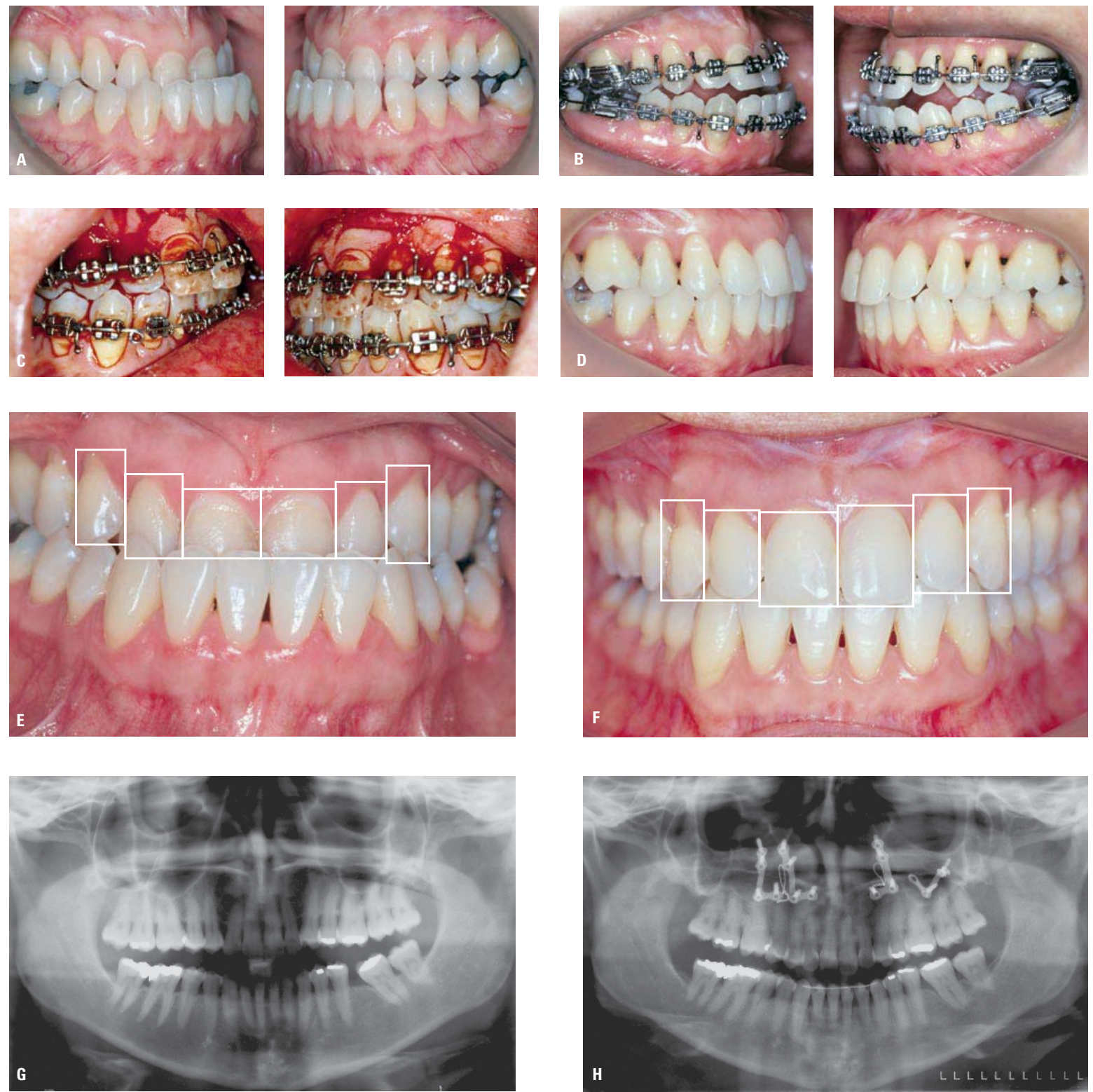

FIGURA 25 - A, B, C, D) - Vistas laterais dos arcos pré-tratamento, pré-cirúrgico, durante a cirurgia e pós-tratamento. E, F) Vistas frontais dos arcos pré e pós-tratamento. G, H) Radiografias panorâmicas pré e pós-tratamento.

\section{Tratamento orto-cirúrgico do Padrão III}

Para facilitar o entendimento dos Diagramas de Referências Estéticas Faciais, serão apresentados casos clínicos de pacientes com necessidades orto-cirúrgicas classificados como Padrão III. Essa escolha se baseou no fato da dificuldade de se diagnosticar, nessa má oclusão, qual estrutura óssea se encontra fora do padrão de normalidade e das suas implicações no tegumento facial, além da necessidade, muitas vezes, de soluções cirúrgicas nos casos de pacientes adultos que possuem esse padrão. 

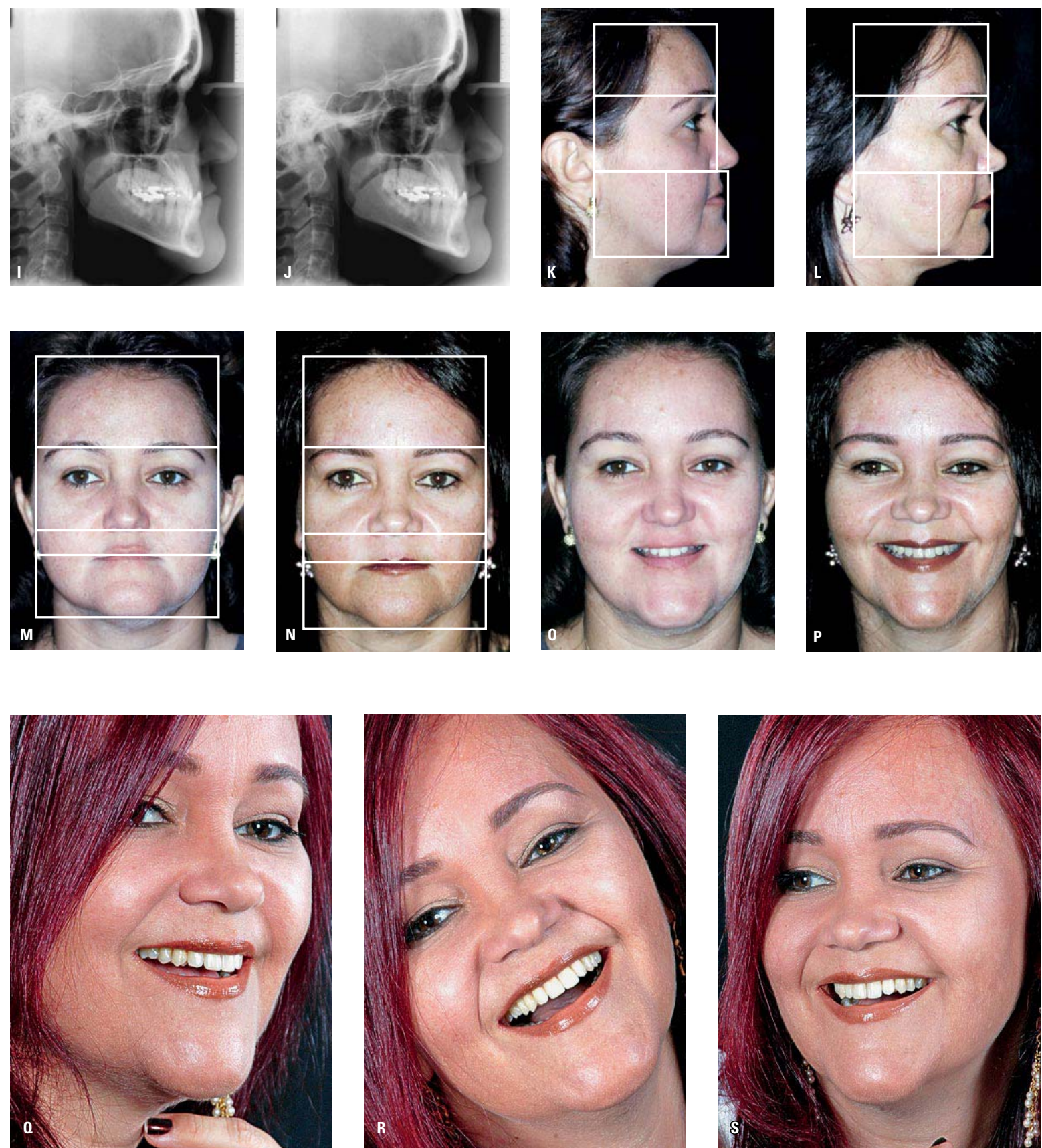

FIGURA 25 - I, J) Telerradiografias pré e pós-tratamento. K, L, M, N) Diagramas de Referências Estéticas Faciais (DREF) pré e pós-tratamento - vistas sagital e frontal. 0) Sorriso pré-tratamento e $\mathbf{P}, \mathbf{Q}, \mathbf{R}$, S) sorriso pós-tratamento.

\section{Posicionamento incorreto da maxila}

Quando se observa uma discrepância sagital, podemos verificar o padrão facial do paciente, ana- lisando as informações obtidas no DREF. Em particular, os casos Padrão III, nos quais a estrutura óssea que se encontra fora da normalidade nem sempre 
é bem visualizada, terão a sua avaliação facilitada com a utilização do DREF. Embora as más oclusões Padrão III sejam, em geral, de fácil visualização, por apresentarem uma tendência à concavidade facial, a identificação se o problema está na maxila ou na mandíbula nem sempre é fácil. Principalmente, por aqueles que não estão familiarizados com a identificação de problemas faciais. O terço médio representará o posicionamento da maxila e o inferior o da mandíbula. Uma maxila atrésica e recuada em relação à mandíbula poderá ser representada pelo recuo do terço médio, em relação aos outros terços, deficiência da projeção zigomática e quase ausência da depressão infraorbitária. Alem disso, a avaliação do terço inferior com a divisão da mandíbula em duas partes, feita pelo limite mandíbula-pescoco, nos dará, também, uma idéia da proporcionalidade e posicionamento da mandíbula na direção vertical e horizontal (Fig. 23).

No caso apresentado, em uma vista sagital, o terço médio se encontrava recuado em relação aos outros dois terços. Isso pode ser evidenciado pelo fato do terço médio se encontrar na mesma linha do terço superior, retruído em relação ao inferior e mostrar uma deficiência da projeção zigomática e quase ausência da depressão infraorbitária. Além disso, a mandíbula não apresentava uma linha mento-pescoço longa. Isto é, não podemos caracterizar a mandíbula como "forte". Em outras palavras, a mandíbula não impressionava a leitura do perfil mole. Numa vista frontal, não se observavam grandes discrepâncias. Apenas o aumento vertical (relativo) do terço inferior, que fica mais bem evidenciado pela desproporção entre lábio superior, lábio inferior e mento, que deveria ser de 1:2. Essa desproporção provoca uma sensação de que a metade do terço inferior está "pesada", principalmente para uma face feminina. O recuo da maxila é quem contribuiu para essa impressão e possivelmente foi potencializado pela ausência dos caninos superiores (Fig. 24).

O planejamento cirúrgico optou pelo avanço da maxila, uma vez que a linha mento-pescoço não indicava a necessidade de recuo da mandíbula. Além disso, a opção pelo simples avanço de maxila apresentou a vantagem de uma menor tendência de recidiva, visto que este tipo de cirurgia é mais estável do que aquela que envolve maxila e mandíbula ${ }^{58}$. O avanço da maxila foi de oito milímetros. A correção da relação oclusal foi obtida posicionando os primeiros pré-molares superiores no lugar dos caninos ausentes. Essa medida levou à necessidade de ajuste oclusal por desgaste nos primeiros pré-molares superiores, para possibilitar guias laterais sem interferências. A utilização do DRED e DREF serviu como referência para harmonizar o complexo dentofacial (Fig. 25).

\section{Posicionamento incorreto de mandíbula}

Quando estamos diante de padrões faciais de difícil interpretação, a utilização do diagrama se mostra bastante útil. A avaliação convencional, feita pela classificação de má oclusão de Angle, nem sempre mostrará a realidade da morfologia facial. $\mathrm{Na}$ Classe III de Angle, o esperado prognatismo mandibular pode ser mascarado pelo excesso vertical da altura inferior da face, ou pode não existir um prognatismo mandibular verdadeiro, estando a causa da doença em uma deficiência maxilar, conforme mostrado no caso anterior. A visualização do erro através do DREF frontal e sagital nos dará uma idéia aproximada de qual desvio da normalidade está ocorrendo (Fig. 26).

Nesse caso, com a utilização do DREF podemos observar que, embora o terço facial inferior esteja retruído em relação aos outros dois terços, o fato se deve ao giro no sentido horário da mandíbula, e o conseqüente aumento vertical desse terço. Poderia seesperarumadeficiênciamaxilar,jáqueéPadrãoIII. Mas esse não é o caso, embora a maxila não possa ser considerada como excelente, também não deveria ser classificada como deficiente. Nessa situação, o procedimento cirúrgico deve visar a correção da discrepância vertical do terço inferior da face, ao mesmo tempo em que regulariza o posicionamento mandibular na direção horizontal. 

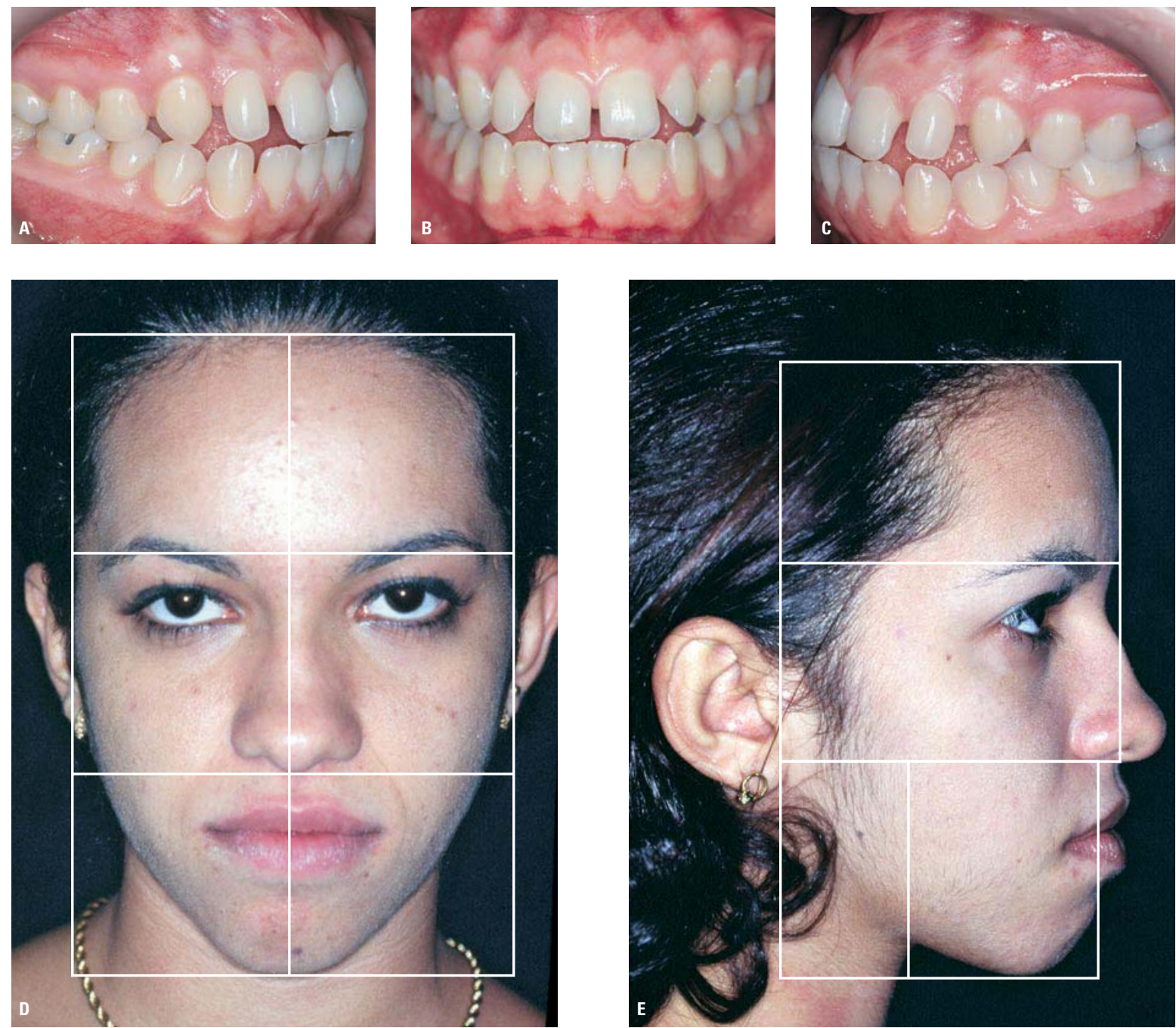

FIGURA 26 - A, B, C) - Vistas laterais e frontal das arcos dentários pré-tratamento. D, E) Diagramas de Referências Estéticas Faciais (DREF) pré-tratamento - vistas frontal e sagital.

Quando o terço médio encontra-se bem posicionado, não apresentando a maxila sinais de atresia, pode-se concluir que o problema está na mandíbula. A visualização das proporções das partes da mandíbula indicava uma discrepância entre ramo e corpo. Esse último, representado pela linha mento-pescoço. Sendo assim, o planejamento cirúrgico foi feito com o intuito de reposicionar apenas a mandíbula. Foi realizado o recuo da mandíbula de $7 \mathrm{~mm}$ e o avanço e intrusão do mento de $5 \mathrm{~mm}$.
$\mathrm{Na}$ fase de finalização pós-cirúrgica, havia uma discrepância do tamanho dos incisivos superiores e inferiores (discrepância de Bolton) ${ }^{8,9}$, com espaços localizados entre os incisivos laterais e caninos superiores.

A utilização do DRED serviu como referência para o aumento da largura mésio-distal dos incisivos laterais superiores com resina composta, obtendo-se, assim, uma proporcionalidade entre os dentes anteriores (Fig. 27). 

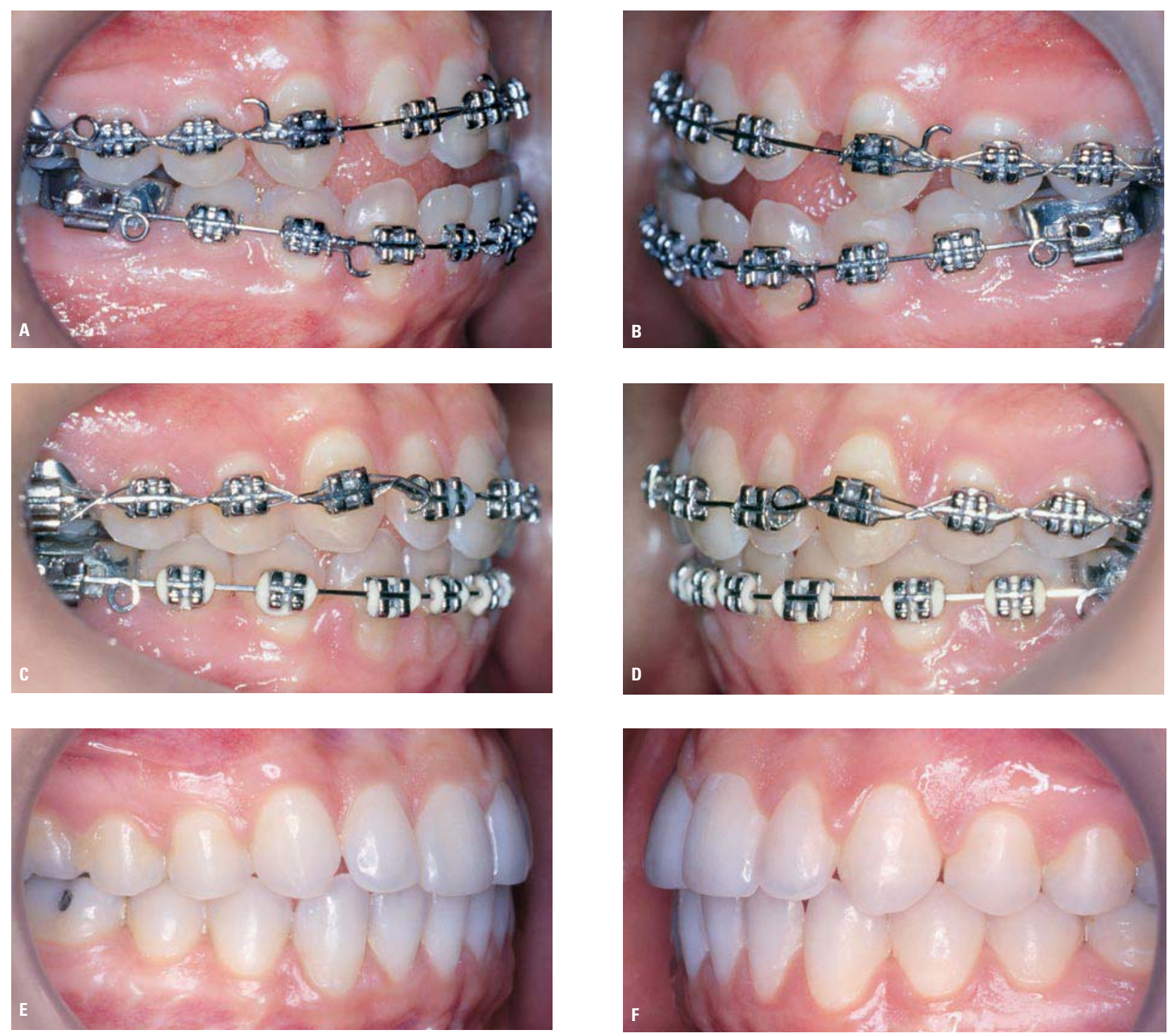

FIGURA 27 - Vistas laterais dos $\operatorname{arcos}$ A, B) pré-cirúrgico, C, D) pós-cirúrgico e E, F) pós-tratamento.

Deve ficar claro que os exemplos de casos cirúrgicos apresentados não foram planejados tendo como referência apenas o DREF. Várias avaliações foram feitas com auxílio de outros exames complementares. No entanto, a intenção foi mostrar que a utilização dos diagramas serviu para auxiliar no diagnóstico e planejamento dos casos, assim como permitiu uma comunicação mais fácil entre profissionais e pacientes.

Como já foi dito, não é intenção do DREF substituir nenhuma das inúmeras análises faciais existentes. Muito menos, servir de parâmetro rígido para o diagnóstico e planejamento de casos clínicos. O DREF, assim como o DRED, tem a intenção de facilitar a visualização das estruturas dentofaciais e melhorar a comunicação entre profissionais das diversas especialidades e desses com os seus pacientes.

\section{CONCLUSÃO}

Os Diagramas de Referências Estéticas Dentárias (DRED) e Faciais (DREF) são indicados para facilitar o diagnóstico e planejamento dos tratamentos odontológicos estéticos e não têm a 

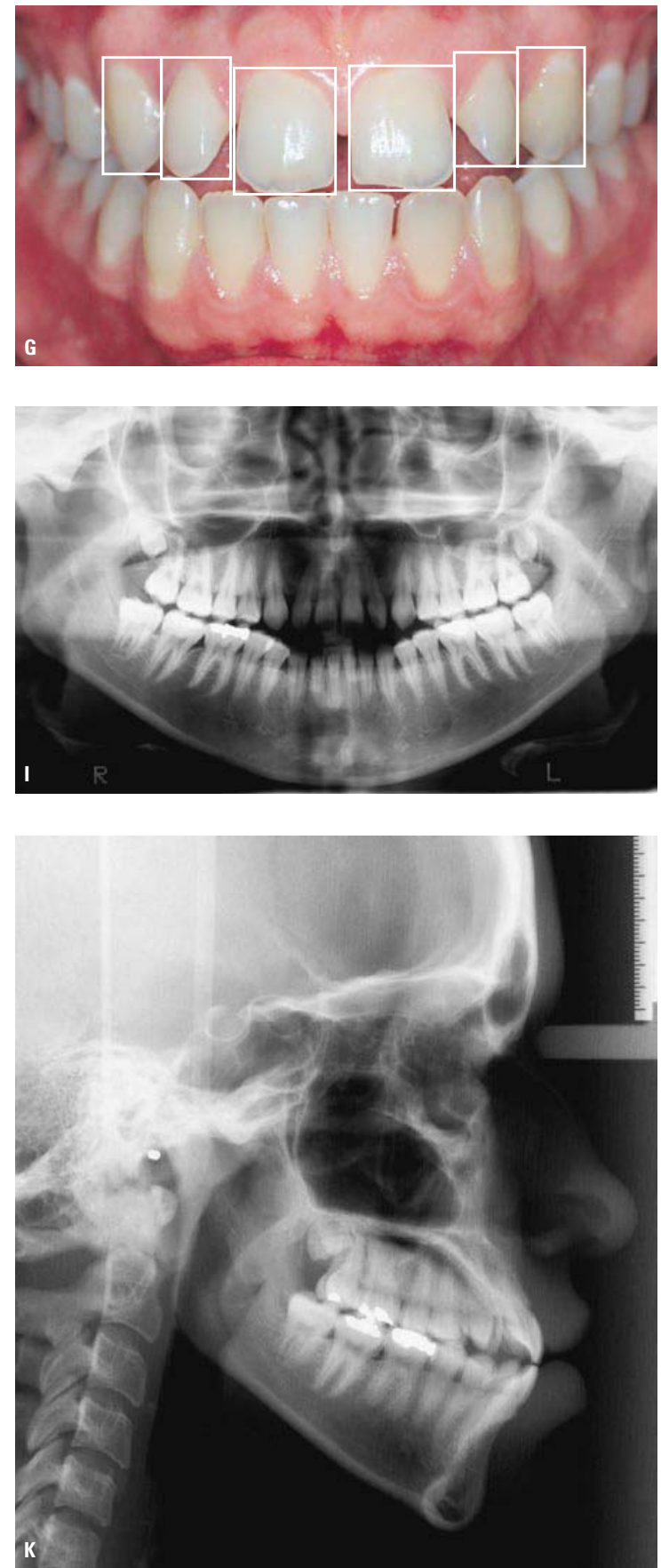

FIGURA 27 - G, H) Diagramas de Referências Estéticas Dentárias (DRED) pré e pós-tratamento. I, J) Radiografias panorâmicas pré e pós-tratamento. K, L) Telerradiografias pré e pós-tratamento.

intenção de serem considerados formas definitivas de análises. O objetivo desses diagramas é facilitar a visualização dos componentes dentofaciais e as suas relações espaciais, dando condições para uma
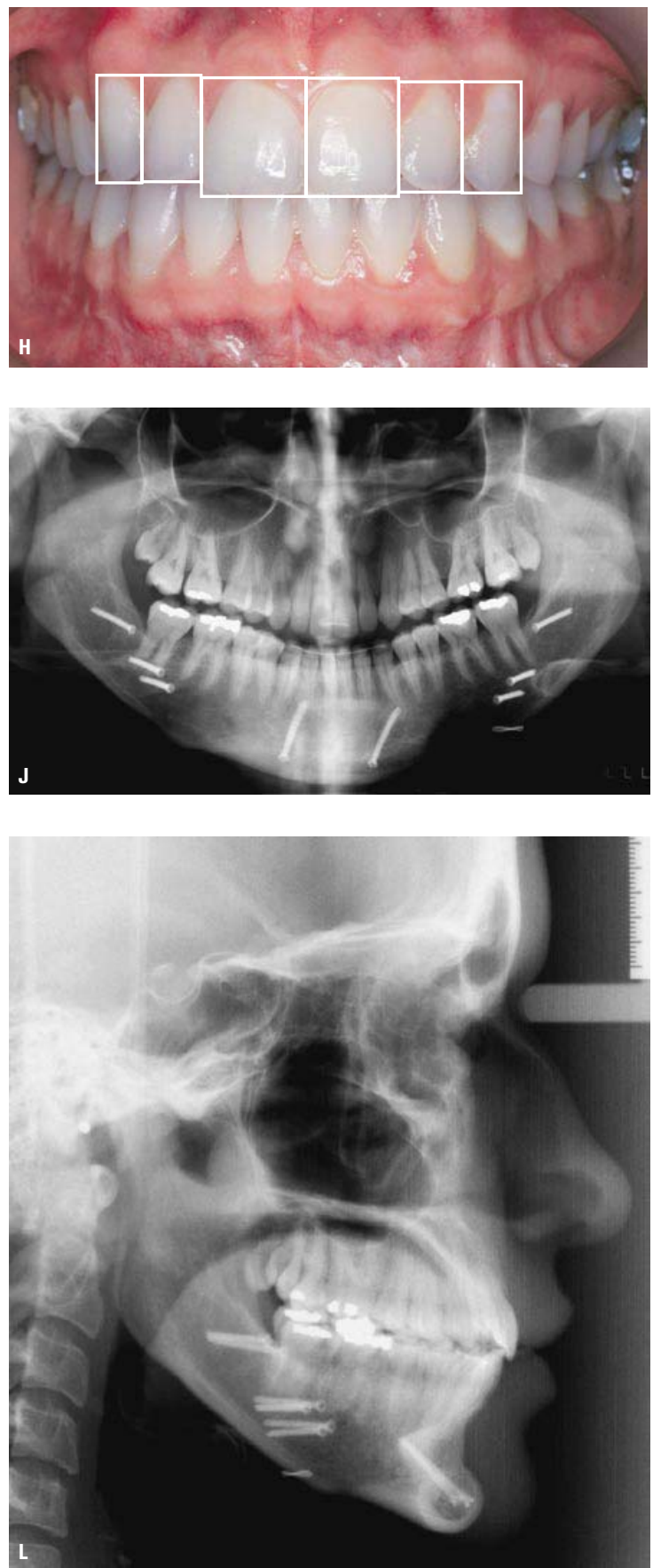

melhor avaliação estética e "artística" desses componentes e, conseqüentemente, permitindo uma maior integração entre as especialidades odontológicas. 

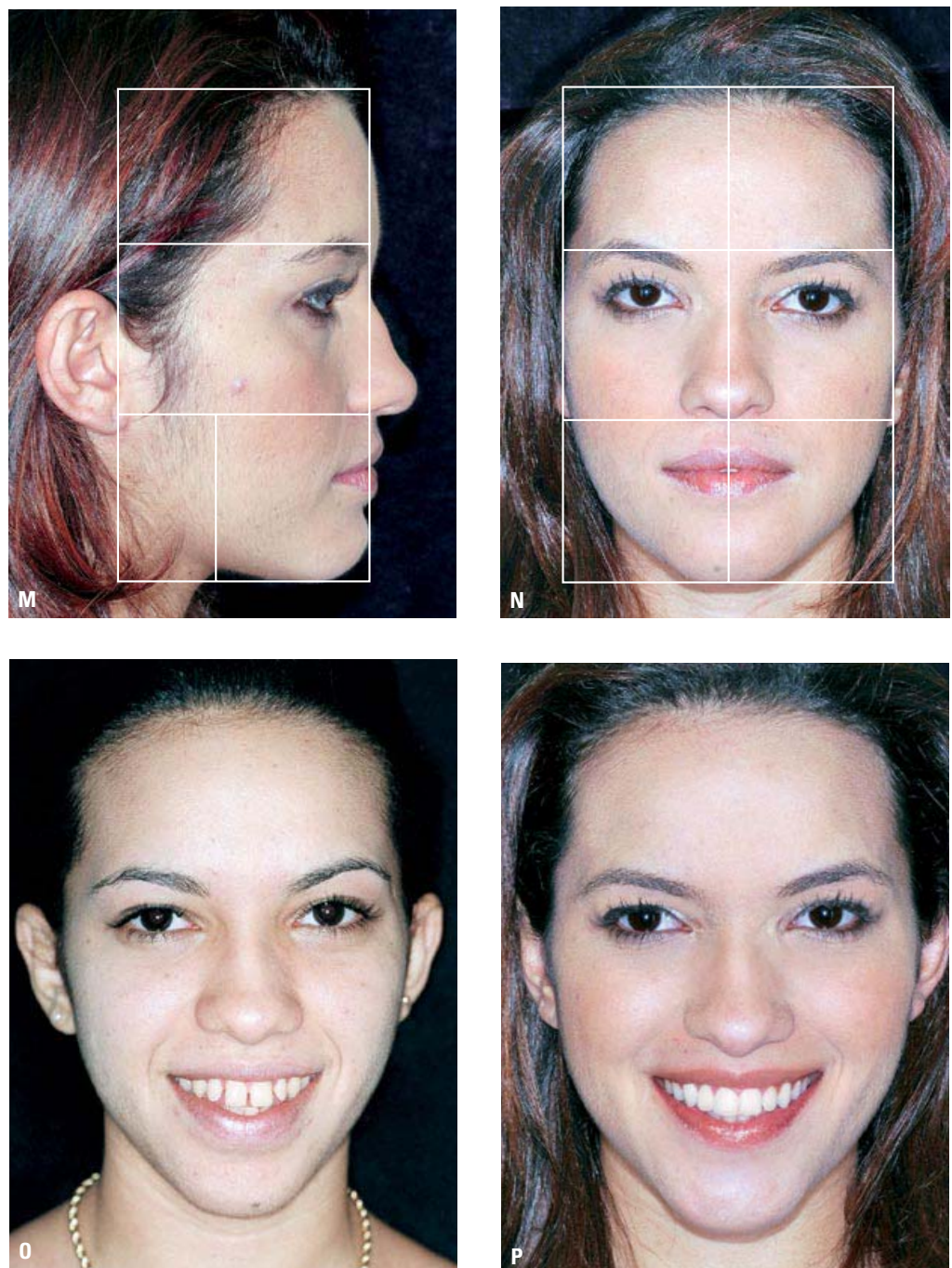

FIGURA 27 - M, N) - Diagramas de Referências Estéticas Faciais (DREF) pós-tratamento - vistas sagital e frontal. O, P) Sorriso pré e pós-tratamento.

\section{AGRADECIMENTOS}

Agradeço aos seguintes profissionais que tiveram uma participação direta ou indireta, fundamental, para a realização desse trabalho:

Dr. Adilson Torreão (Recife/PE);

Dr. Adilson dos Santos Torreão (Recife/PE);

Dr. Aldino Puppin (Vitória/ES);

Dr. Dickson Fonseca (Natal/RN);

Dra. Ione Cabral (Natal/RN);

Dr. Jolber Fonseca (Natal/RN);

Dra. Keila Meira (Natal/RN);

Dra. Nia Torquato (Natal/RN);

Dr. Sérgio Varela (Natal/RN);

Dra. Simone Fujiwara (Natal/RN);

Dra. Silvia Reis (São Paulo/SP);

Dudu Medeiros (fotógrafo - São Paulo/SP);

Paulo Oliveira (fotógrafo - Natal/RN).
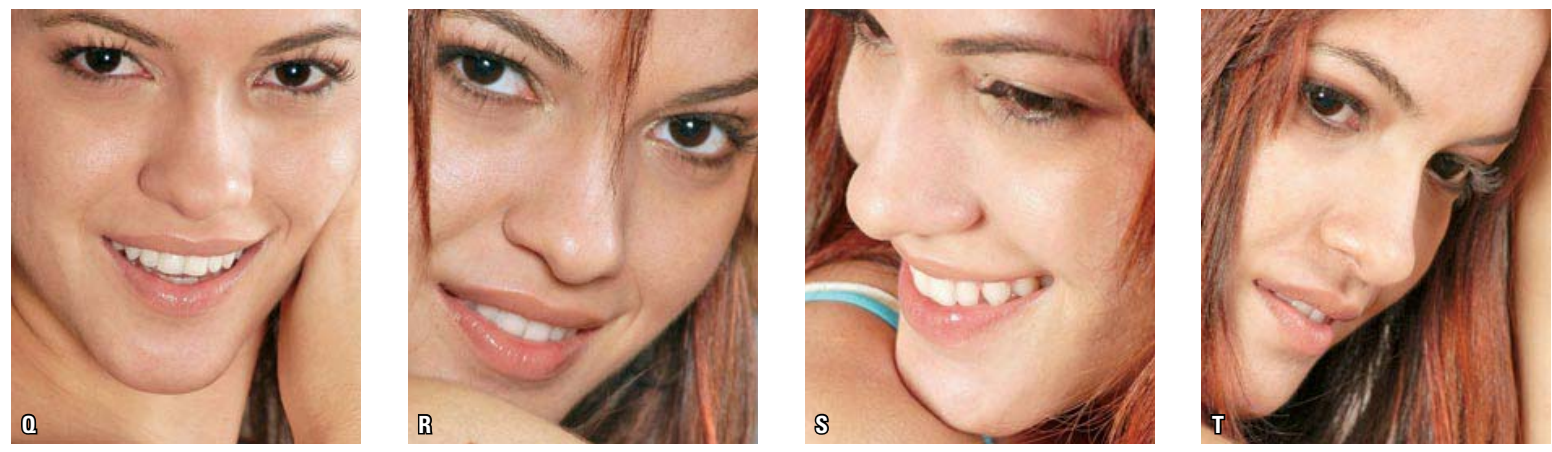

FIGURA 27 - 0, R, S, T) Equilibrio da estética dentária, bucal e facial. Cirurgia Ortognática executada pelo Dr. Sérgio Varela. Resinas compostas executadas pela Dra. Simone Fujiwara (foto Paulo Oliveira). 


\title{
Aesthetics in Orthodontics: Diagrams of Facial Aesthetic References (DFAR) and Diagrams of Dental Aesthetic References (DDAR)
}

\author{
Abstract \\ It would be interesting if all odontological specialties engaged in the Esthetic Dentistry could use dental and fa- \\ cial esthetics parameters common to all professionals. Considering that this task will only be performed when the \\ specialties can count upon a simplified esthetic analysis that everybody understands, this study aim to show Dental \\ and Facial Esthetic References Diagrams in order to help both the diagnosis and planning of multidisciplinary treat- \\ ments.
}

Key words: Aesthetic dentistry. Orthodontics. Facial aesthetics.

\section{REFERÊNCIAS}

1. ANDREWS, L. F. Straight-Wire: the concept and appliance. San Diego: L.A. Wells, 1989

2. ANDREWS, L. F. The six keys to normal occlusion. Am J Orthod St. Louis. v. 62, no. 3, p. 296-309, Sept. 1972

3. ARNETT, W. G.; BERGMAN, R. Facial keys to orthodontic diag nosis and treatment planning - Part I. Am J Orthod Dentofacial Orthop, St. Louis, v.103, no. 4, p.299-312, Apr. 1993.

4. ARNETT, W. G.; BERGMAN, R. Facial keys to orthodontic diagnosis and treatment planning - Part II. Am J Orthod Dentofacial Orthop, St. Louis, v. 103, no. 5, p. 395-411, May 1993.

5. AUGER, T. A.; TURLEY, P. K. The female soft tissue profile as presented in fashion magazines during the 1990s: A photografic analyzis. Int J Oral Surg, Copenhagen, v. 14, no. 1, p. 7-18, 1999.

6. BELSER, U. C. Esthetics checklist for the fixed prothesis. Part II. Biscuit-bake try-in. In: SCHÄRER, P.; RINN, L. A.; KOPP, F. R. Esthetic guidelines for restorative dentistry. Chicago: Quintessence, 1982. p. 188-192.

7. BLOOM, L. A. Perioral profile changes in orthodontic treatment Am J Orthod, St. Louis, v. 47, no. 5, p. 371-379, May 1961.

8. BOLTON, W. A. Disharmony in tooth size and its relation to the analysis and treatment of malocclusion. Angle Orthod, Appleton, v. 28, no. 3, p.113-130, July 1958.

9. BOLTON, W. A. The clinical use of a tooth size analysis. Am J Orthod, St. Louis, v. 48, no. 5, p. 504-529, July 1962

10. BURSTONE, C. J. Integumental contour and extension patterns. Angle Orthod, Appleton, v. 29, no. 2, p. 93-104, Apr. 1959.

11. BURSTONE, C. J. Lip posture and its significance in treatment planning. Am J Orthod, St. Louis, v. 53, no. 4, p. 262-284, Apr. 1967

12. CÂMARA, C. A. L. P.; FONSECA, D. M. Tratamento integrado de reabilitação oral em paciente adulto. $\mathbf{R}$ Clin Ortodon Dental Press, Maringá, v. 3, n.1, p. 83-90. fev./mar. 2004

13. CÂMARA, C. A. L. P.; FONSECA, D. M.; FAHL JR., N. Abordagem interdisciplinar para o tratamento de diastema. Est Contemp, [s.I.], v. 1, no. 1, p. 51-57, 1999

14. CÂMARA, C. A. L. P.; FONSECA. D. M. Tratamento interdisciplinar - ajuste estético de casos ortodônticos atípicos. R Dental Press Ortodon Ortop Facial, Maringá, v. 5, n. 5, p. 68-74, set./out. 2000.

15. CAPELOZZA FILHO, L. Diagnóstico em Ortodontia. Maringá: Dental Press, 2004

16. CAPELOZZA FILHO, L. et al. Individualização de braquetes na técnica de straight-wire: revisão de conceitos e sugestões de indicações para uso. R Dental Press Ortodon Ortop Facial Maringá, v. 4, no. 4, p. 87-106, jul./ago.1999.

17. $\mathrm{CHICHE}$, et al. Diagnosis and treatment planning of esthetic problem. In: CHICHE, G.; PINAULT, A. Esthetics of anterio fixed prosthodontics. St. Louis: Quintessence, 1994. p. 33-52.
18. CHICHE, G.; PINAULT, A. Artistic and scientific principles applied to esthetic dentistry. In: CHICHE, G.; PINAULT. A. Esthetics of anterior fixed prosthodontics. St. Louis: Quintessence, 1994. p. 13-32.

19. CHIU, C. S. W.; CLARK, R. K. F. Reproducibility of natural head position. J Dent, Bristol, v. 19, p. 130-131, 1991

20. CLAMAN, L.; PATTON, D.; RASHID, R. Standardized portrait photography for dental patients. Am J Orthod Dentofacial Orhtop, St. Louis, v. 98, no. 3, p. 197-205, Sept. 1990.

21. COOKE, M. S. Five - year reproducibility of natural head posture: a longitudinal study. Am J Orthod Dentofacial Orthop St. Louis, v. 97, n. 6, p. 489-494, June 1990.

22. COOKE, M. S.; WEI, S. H. Y. The reproducibility of natural head posture. A methodological study. Am J Orthod Dentofacial Orthop, St. Louis, v. 93, no. 4, p. 280-288, Apr. 1988.

23. DUNN, W. J.; MURCHISON, D. F.; BROOME, J. C. Esthetics: patient perceptions of dental attractiveness. J Prosthodont, Copenhagen, v. 5, no. 3, p. 166-171, Sept.1996.

24. EDDS, C. W. Determination of lip position in esthetics profiles. Am J Orthod, St. Louis, v. 50, no. 10, p. 783-784, Oct. 1964.

25. EPKER, B. N.; STELLA, J. P.; FISH, L. C. Dentofacial deformities integrated orthodontic and surgical correction. 2 nd ed. Mosby: [s.n.], 1995. p. 8-11.

26. FEIGENBAUM, N. L. Aspects of aesthetic smile design. Pract Periodontics Aesthet Dent, Mahwah, v. 3, no. 3, p. 9-13, Apr./May 1991.

27. FERRARIO, V. F. et al. A three-dimensional evaluation of human acial asymmetry. J Anat, Oxford, v. 186, p. 103-110, 1995.

28. FERRARIO, V. F. et al. Craniofacial morphometry by photographic evaluations. Am J Orthod Dentofacial Orthop, St. Louis, v. 103, no. 4, p. 327-337, Apr. 1993.

29. FERREIRA A. B. H. Novo Aurélio século XXI: o dicionário da língua portuguesa. 3. ed. Rio de Janeiro: Nova Fronteira, 1999.

30. FIELDS, H. W. Orthodontic-restorative treatment for relative mandibular anterior excess tooth-size problems. Am J Orthod Dentofacial Orthop, St. Louis, v. 79, no. 2, p. 176-183, Feb. 1981.

31. GÜREL, $G$. The science and art of porcelain laminate veneers Berlin: Quintessence, 2003.

32. HEES, D.; MAGNE, P.; BELSER, U. Combined periodontal and prosthetic treatment. Schweis Monatsschr Zahnmed, Bern, v. 104, no. 9, p. 1109-1115, 1994.

33. HEINLEIN, W. D. Anterior teeth: esthetics and function. J Prosthet Dent, St. Louis, v. 44, no. 4, p. 389-393, Oct. 1980.

34. HERZBERG, B. L. Facial esthetic in relation to orthodontic treatment. Angle Orthod, Appleton, v. 22, no.1, p. 3-22, Jan. 1952

35. JOHNSTON, C. D.; BURDEN, D. J.; STEVENSON, M. R. The influence of dental to facial midline discrepancies on dental attractiveness ratings. Eur J Orthod, Oxford, v. 21, no. 5, p. $517-522,1999$

36. KAWAMOTO JR., H. K. Treatment of the elongated lower face and the gummy smile. Clin Plast Surg, Philadelphia, v. 9, no. 4 p. 479-489, Oct. 1992. 
37. KOKICH JR V. O. KIYAK H. A.; SHAPIRO P. A. Comparing the perception of dentists and lay people to altered dental esthetics. J Esthet Dent, Hamilton, v. 11, no. 6, 1999.

38. LEGAN, H. L.; BURSTONE, C. J. Soft tissue cephalometric analysis for orthognathic surgery. J Oral Surg, Chicago, v. 38, n. 10 p. 744-751, Oct. 1980

39. LEHMAN JR., J. A. Soft - tissue manifestations of aesthetic defects of the jaws: diagnosis and treatment. Clin Plast Surg, Philadelphia, v. 14, no. 4, p. 767-783, Oct. 1987.

40. LEVIN, E. L. Dental esthetics and the golden proportion. J Prosthet Dent, St. Louis, v. 40, no. 3, p. 244-252, Sept. 1978.

41. LEVINE, R. A.; McGUIRE, M. The diagnosis and treatment of the gummy smile. Compend Contin Educ Dent, Lawrenceville, v. 18 , no. 8, p. 757-766, Aug. 1997

42. LOMBARDI, R. E. The principles of visual perception and their clinical application to denture esthetics. J Prosthet Dent St. Louis, v. 29, no. 4, p. 358-382, Apr. 1973

43. LUNDSTRÖM, A.; FORSBERG, C. M.; WESTERGREN, H.; LUNDS TRÖM, F. A comparison between estimated and registered natural head posture. Eur J Orthod, Oxford, v. 13, p. 59-64, 1991

44. LUNSDSTRÖM, A.; LUNDSTRÖM, F.; LEBRET, L. M. L: MOORREES, C. F. A. Natural head posture and natural head orientation: basic considerations in cephalometric analysis and research. Eur J Orthod, Oxford, v. 17, no. 2, p. 111-120, Apr. 1995

45. MAGNE, P. BELSER, U. Restaurações adesivas de porcelan na dentição anterior: uma abordagem biomimética. São Paulo: Quintessence, 2003

46. MATTHEWS, T. G. The anatomy of a smile. J Prosthet Dent, St Louis, v. 39, n. 2, Feb. 1978

47. MILLER, E. L.; BODDEN, J. R.; W. R.; JAMISON, H. C. A study of the relationship of the dental midline to the facial median line. J Prosthet Dent, St. Louis, v. 41, no. 6, p. 657-660, June 1979

48. MITANI, H. Preburbertal growth of mandibular prognatism. Am J Orthod, St. Louis, v. 80, no. 5, p. 546-553, Nov. 1981

49. MITANI, H.; SATO, K.; SUGAWARA, J. Growth of mandibular prognatism after pubertal growth peak. Am J Orthod Dentofacial Orthop, St. Louis, v. 104, no. 4, p. 330-336, Oct. 1993

50. MORLEY, J.; EUBANK, J. Macro esthetic elements of smile design J Am Dent Assoc, Chicago, v. 132, no. 1, p. 39-45, Jan. 2001

51. MORRIS, W. An orthodontic view of dentofacial esthetics. Compend Contin Educ Dent, Lawrenceville, v. 15, no. 3, p. 378-390, 1994.

52. NANDA, R. S.; GHOSH, J. Harmonia entre os tecidos moles da face e o crescimento no tratamento ortodôntico. In: SADOWSKY, P. L. et al. Atualidades em Ortodontia. São Paulo: Premier, 1997. p. 65-78.

53. PECK, S.; PECK, L. Aspectos selecionados da arte e da ciência da estética facial. In: SADOWSKY, P. L. et al. Atualidades em Ortodontia. São Paulo: Premier, 1997. p. 65-78; 1997.

54. PECK, S.; PECK, L.; KATAJA, M. Some vertical lineaments of lip position. Am J Orthod Dentofacial Orthop, St. Louis, v. 101, no. 6, p. 519-524, June 1992

55. PECK, S.; PECK, L.; KATAJA, M. The gengival smile line. Angle Orthod, Appleton, v. 62, no. 2, p. 91-100, 1992.
56. PENG, L.; COOKE, M. S. Fifteen-year reproducibility of natural head posture: a longitudinal study. Am J Orthod Dentofacial Orthop, St. Louis, v. 116, no. 1, p. 82-85, July 1999.

57. PRESTON, J. D. The golden proportion revisited. J Esthet Dent, Philadelphia, v. 5, no. 6 p. 247-251, 1993.

58. PROFFIT, W. R.; TURLEY, T. A.; PHILLIPS, C. Orthognathic surgery a hierarchy of stability. Int J Adult Orthodon Orthognath Surg, Chicago, v. 2, no. 3, p. 191-204, 1996.

59. PUPPIN, A. F. Avaliação quantitativa de medidas dento-faciais relacionadas à altura da linha do sorriso. 2002. $122 \mathrm{f}$. Dissertação (Mestrado)-Faculdade de Odontologia da Universidade do Estado do Rio de Janeiro, Rio de Janeiro, 2002.

60. REIS, S. A. B. Análise facial numérica e subjetiva do perfil e análise da relação oclusal sagital em brasileiros, adultos, leucodermas, não tratados ortodonticamente. 2001. Dissertação (Mestrado)- UMESP, São Paulo, 2001

61. RICKETTS, R. M. Planning treatment on the basis of the facial pattern and an estimate of its growth. Angle Orthod, Appleton, v. 27 , no. 1, p. 14-37, Jan. 1957.

62. RUBIN, L. R. The anatomy of a smile: its importance in the treatment of facial paralysis. Plast Reconstr Surg, Hagerstown, v. 53 no. 4, p. 384-387, Apr. 1974.

63. RUFENACHT, C. R. Fundamentos de estética. In: RUFENACHT, C. R. Normas estéticas estruturais. São Paulo: Quintessence. 1998. p. 67-134.

64. SAKAMOTO, E. et al. Craniofacial growth of mandibular prognatism during pubertal growth period in Japonese boys: longitudinal study from 10 to 15 yaers of age. J Japan Orthod Soc [s.I.], v. 5, no. 5 , p. $372-286,1996$

65. SARVER, D. M. The importance of incisor positioning in the esthetic smile: the smile arc. Am J Orthod Dentofacial Orthop, St. Louis, v. 120, no. 2, p. 98-111, Aug. 2001

66. SARVER, D. M.; ACKERMAN, M. B. Dynamic smile visualization and quantification: Part 1. Evolution of the concept and dynamic records for smile capture. Am J Orthod Dentofacial Orthop St. Louis, v. 124, no. 1, p. 4-12, July 2003.

67. SULIKOWSKI, A.; YOSHIDA, A. Three-dimensional management of dental proportions: a new esthetic principle - "The frame of reference". Quintessence Dent Technol, Chicago, v. 25, p. 8-20, 2002.

68. TERRY, R. L.; DAVIS, J. S. Components of facial attractiveness. Percept Mot Skills, Missoula, v. 42, p. 918, June 1976.

69. TJAN, A. H.; MILLER, G. D. Some esthetic factors in a smile. J Prosthet Dent, St. Louis, v. 51, no. 1 p. 24-28, Jan. 1984

70. TWEED, C. H. The diagnostic facial triangle in the control of treatment objectives. Am J Orthod, St. Louis, v. 55, no. 6, p. 651-667, June 1969

71. VIG, R. G.; BRUNDEL, G. C. Kinetics of anterior tooth display. J Prosthet Dent, St. Louis, v. 39, no. 5, p. 502-504, May 1978.

72. ZACHRISSON, B. U. Esthetic factors involved in anterior tooth display and the smile: vertical dimension. J Clin Orthod, Boulder, v. 32, n. 9, p. 432-445, Sept. 1998.

73. ZAREM, H. A. Standards of photography. Plast Reconstr Surg Hagerstown, v. 74, no. 1, p. 137-144, 1984.

\author{
Endereço de correspondência \\ Carlos Alexandre Leopoldo Peersen da Câmara \\ Av. Campos Sales 631, Tirol \\ CEP. $59.020-300$ - Natal/RN \\ E-mail: cac.ortodontia@digi.com.br
}

